\title{
Avaliação da eficácia e segurança do emprego do tramadol para analgesia em cães portadores de dor oncológica
}

Dissertação apresentada ao Programa de PósGraduação em Clínica Cirúrgica Veterinária da Faculdade de Medicina Veterinária e Zootecnia da Universidade de São Paulo para obtenção do título de Mestre em Medicina Veterinária

Departamento:

Cirurgia

Área de concentração:

Clínica Cirúrgica Veterinária

Orientadora:

Prof $^{\mathrm{a}} \mathrm{Dr}^{\mathrm{a}}$ Denise Tabacchi Fantoni 
Autorizo a reprodução parcial ou total desta obra, para fins acadêmicos, desde que citada a fonte.

\section{DADOS INTERNACIONAIS DE CATALOGAÇÃO-NA-PUBLICAÇÃO}

(Biblioteca Virginie Buff D’Ápice da Faculdade de Medicina Veterinária e Zootecnia da Universidade de São Paulo)

T.1761

FMVZ
Flôr, Patrícia Bonifácio

Avaliação da eficácia e segurança do emprego do tramadol para analgesia em cães portadores de dor oncológica / Patrícia Bonifácio Flôr. São Paulo: P. B. Flôr, 2006.

$88 \mathrm{f}$ : : il.

Dissertação (mestrado) - Universidade de São Paulo. Faculdade de Medicina Veterinária e Zootecnia. Departamento de Cirurgia, 2006.

Programa de Pós-graduação: Clínica Cirúrgica Veterinária.

Área de concentração: Clínica Cirúrgica Veterinária.

Orientador: Profa. Dra. Denise Tabacchi Fantoni.

1. Cães. 2. Oncologia veterinária (tratamento)

3. Analgesia.

4. Opióides. 5. Dor (tratamento). I. Título. 


\section{UNIVERSIDADE DE SÃO PAULO \\ Faculdade de Medicina Veterinaria e Zootecnia \\ Assistência Acadêmica}

Comissão de Bioética

\section{CERTIFICADO}

Certificamos que o Projeto intitulado "Avaliação da eficácia, efetividade e segurança do uso do tramadol para o controle da dor em cães portadores de dor oncológica", protocolo $n^{\circ} 690 / 2005$, utilizando 70 cães, sob a responsabilidade da Prof $^{a}$ Dr $^{a}$ Denise Tabacci Fantoni , está de acordo com os princípios éticos de experimentação animal da Comissão de Bioética da Faculdade de Medicina Veterinária e Zootecnia da Universidade de São Paulo e foi aprovado "ad referendun".

(We certify that the Research "Evaluation of effectiveness and security of the use of tramadol for the control of pain in dogs with oncology pain", protocol number 690/2005, utilizing 70 dogs, under the responsibility of Profa ${ }^{a} r^{a}$ Arani Nanci Bomfim Mariana, agree with Ethical Principles in Animal Research adopted by Bioethic Commission of the Faculty of Veterinary Medicine and Zootechny of University of São Paulo and was approved "ad referendun", meeting).

São Paulo, 01 de junho de 2005

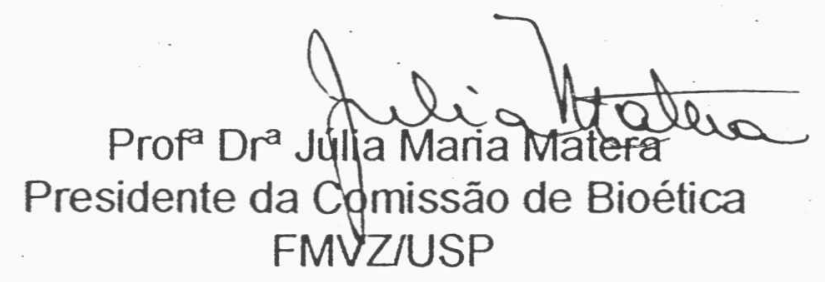




\section{FOLHA DE AVALIAÇÃO}

Nome: FLÔR, Patrícia Bonifácio

Título: Avaliação da eficácia e segurança do emprego do tramadol para analgesia em cães portadores de dor oncológica

Dissertação apresentada ao Programa de PósGraduação em Clínica Cirúrgica Veterinária da Faculdade de Medicina Veterinária e Zootecnia da Universidade de São Paulo para obtenção do título de Mestre em Medicina Veterinária

Data:

Banca Examinadora

Prof. Dr.

Assinatura:

Prof. Dr.

Assinatura:

Prof. Dr.

Assinatura:
Instituição:

Julgamento:

Instituição:

Julgamento:

Instituição:

Julgamento: 


\section{DEDICATÓRIA}

Aos meus pais, Osnir e Inês, por serem a razão e porquê de tudo que conquistei e sou.

Aos meus irmãos, Ricardo e Rodrigo, pelo apoio incondicional em todos os momentos, pela amizade e carinho de sempre.

À Professora Denise Fantoni, profissional brilhante, alegre e determinada. Obrigada, não só por ter acreditado em mim e pelas oportunidades oferecidas, mas principalmente pela sua amizade. 


\section{AGRADECIMENTOS}

À Universidade de São Paulo, pela acolhida durante todos estes anos de estudo.

À Professora Silvia Cortopassi, por todos os ensinamentos, amizade, conselhos e constante apoio desde a graduação.

À Professora Júlia Matera, exemplo de dedicação aos animais e a Medicina Veterinária.

Ao Professor Ângelo Stopiglia e ao Professor Paulo Sérgio de Moraes Barros, exemplos de profissionais e seres humanos.

Ao Professor Gioso pelo incentivo e apoio desde da graduação.

À todos os Professores da FMVZ-USP pelo convívio e apoio.

À todos os animais que contribuíram para a realização este estudo e a seus proprietários que participaram, aprendendo e ensinando como reconhecer a de seus companheiros.

À Karina Yazbek pela amizade, dedicação e companheirismo fundamentais para a realização deste projeto. Muito obrigado por tudo.

À Teresinha Martins, uma amizade recente, porém sincera e de muito companheirismo. Obrigada pelo apoio constante.

À amiga de longa data Raquel Sartorelli, pela amizade incondicional que sempre me apoiou nos momentos bons e ruins.

Ao amigo Rafael Costa Jorge, com quem aprendi muito na rotina do Serviço de Anestesia.

Às médicas veterinárias contratadas do Serviço de Cirurgia Andressa, Tatiana, Sandra, Patrícia e Viviane, pelo constante apoio, confiança e amizade durante a realização deste projeto.

Às (os) Médicas (os) Veterinárias (os) contratadas (os) Denise, Paula, Bruna, Júlia, Kadhine, Silvana, Luciane, João, Rodrigo, Angélica, Mary, Valéria, Maria Luiza, Marcelo e Mariana. Ao Ney, sempre disposto a ajudar e resolver todos os problemas.

Aos funcionários Jesus, Otávio, Lélis, Maurício, Henrique, Miron, Nice, Laércio e Nelson, sempre dispostos a ajudar.

À FAPESP pelo apoio financeiro.

À todas as pessoas que direta ou indiretamente colaboraram para a realização deste projeto. 


\section{RESUMO}

FLÔR, P. B. Avaliação da eficácia e segurança do emprego do tramadol para analgesia em cães portadores de dor oncológica. [Evaluation of effectiveness and security of the tramadol for the analgesia in dogs with oncologic pain]. 2006. $88 \mathrm{f}$. Dissertação (Mestre em Medicina Veterinária) - Faculdade de Medicina Veterinária e Zootecnia, Universidade de São Paulo, São Paulo, 2006.

O câncer é a maior causa de morbidade e mortalidade em animais idosos de companhia, sendo a dor o principal sintoma relatado no homem. Objetivou-se, neste estudo, avaliar o emprego do tramadol para analgesia em cães com dor oncológica. Foram avaliados cães com câncer no período de agosto de 2004 a março de 2006, encaminhados ao Grupo de Dor do Serviço de Anestesia. Incluiu-se no estudo cães que permaneceram no mínimo 15 dias em tratamento e que, no momento de instituição da terapêutica com o tramadol, apresentaram dor igual ou maior que 4, de acordo com Escala Numérica Verbal (ENV) quando já medicados com dipirona associada ou não a antiinflamatórios não esteroidais ou esteroidais há mais de 10 (dez) dias. Avaliou-se a dor com a ENV e o escore de qualidade de vida (QV) através de escala validada para cães (Yazbek; Fantoni, 2000). Foram avaliados para o estudo 130 animais com câncer, 53 machos e 77 fêmeas, dos quais 37 obedeceram aos critérios de inclusão para análise da terapia analgésica. De acordo com a avaliação dos proprietários, a média de dor dos animais avaliados pela da ENV no momento de instituição da terapêutica com o tramadol foi de $6,11 \pm 1,81$ e o escore de qualidade de vida foi $21,95 \pm 5,96$. No primeiro retorno verificou-se melhora da dor em $31(83,78 \%)$ animais. Neste momento foi realizada adequação da dose do tramadol, considerando-se a intensidade da dor em 20 $(54,05 \%)$ dos 37 cães era superior a 4. No segundo retorno 34 (91,89\%) dos animais apresentaram alívio da dor em relação à consulta inicial, sendo que 28 (75,68\%) destes obtiveram ENV inferior a 4. A dose inicial preconizada do tramadol foi de $2 \mathrm{mg} / \mathrm{Kg}$ a cada 8 horas, por via oral, sendo esta dose reajustada no retorno caso o valor de ENV fosse maior que 4. Classificando a eficácia do tratamento realizado com o tramadol em três categorias: alívio da dor $($ ENVinicial $>$ ENVfinal e ENVfinal $<4)$, melhora insatisfatória $($ ENVinicial > ENVfinal e ENVfinal $>4$ ) e ausência de melhora (ENVinicial $\leq$ ENVfinal) pode-se afirmar que no primeiro retorno $83,78 \%$ e $78,28 \%$ dos pacientes, na opinião de proprietário e pesquisador respectivamente, experimentaram alguma melhora da dor. Seguindo esta mesma classificação observou-se que, no segundo retorno após acerto da dose do tramadol, o alívio da dor foi obtido em $28(75,68 \%)$ animais na opinião de proprietário e pesquisador e melhora 
insatisfatória em $6(16,21 \%)$ e $7(18,91 \%)$ pacientes, de acordo com o proprietário e pesquisador respectivamente. Quando comparados os grupos separadamente verifica-se que o grupo DAINET (dipirona, AINE, tramadol) apresentou significante alívio da dor em relação ao primeiro retorno e a avaliação final, já os grupos DT (dipirona, tramadol) e DET (dipirona, esteróide, tramadol) apresentaram alívio da dor apenas em relação a avaliação final. Com base no alívio da dor e no aumento da qualidade de vida, pode-se concluir que o tramadol foi eficiente no tratamento da dor de grau moderada à intensa em cães portadores de câncer.

Palavras-chave: Cães. Oncologia Veterinária (tratamento). Analgesia. Opióides. Dor (tratamento). 


\begin{abstract}
FLÔR, P. B. Evaluation of effectiveness and security of the tramadol for the analgesia in dogs with oncologic pain [Avaliação da eficácia e segurança do emprego do tramadol para analgesia em cães portadores de dor oncológica]. 2006. 88 f. Dissertação (Mestrado em Medicina Veterinária) - Faculdade de Medicina Veterinária e Zootecnia, Universidade de São Paulo, São Paulo, 2006.
\end{abstract}

Cancer is the main cause of morbidity and mortality in companion aged dogs, being pain the principal symptom described in humans. This study aimed to evaluate the use of tramadol for analgesia in dogs with oncologic pain. Between august 2004 and marc 2006, dogs with cancer referred to the Pain Group of the Anesthesia Service were evaluated. In this study, dogs with at least fifteen days of treatment were included and that at the moment at tramadol administration, presented pain equal or above 4 according the Visual Analogue Scale (VAS) when treated with dypirona associated our not to non-esteroidal anti-inflammatory analgesics or steroidal for more than 10 days. Pain evaluated with the VAS and the quality of life (QV) score validated for dogs (Yazbek; Fantoni, 2000) were used. One hundred and thirty seven dogs with cancer were evaluated, but only 37 could be included the evaluation of analgesic therapy. According to the owner of the animals by means of the VAS at the begging of tramadol was 6,11 $\pm 1,81$ and the QV score was 21,95 $\pm 5,96$. At the first return, an improvement in pain was verified in 31 animals (83,78\%). In this moment, adequacy of tramadol dose was performed, since the intensity of pain was above 4 in 20 (54,05\%) animals. At the second returns 34 (91,89\%) of the animals presented pain relief in relation to the first visit, being that $28(75,68 \%)$ of the animal presented a VAS bellow 4 the initial dose $o$ tramadol was $2 \mathrm{mg} / \mathrm{Kg}$ each 8 hours orally, and the dose was readjusted in the return who the animal presented VAS above 4. Efficacy of treatment was classified in the three steps pain relief: successful pain relief (initial VAS > final VAS and final VAS $<4$ ), unsuccessful pain relief (initial VAS $>$ final VAS and final VAS $>4$ ) and no pain relief (initial VAS $\leq$ final 
VAS). It could be inferred that at the first return $83,78 \%$ and $78,28 \%$ of patients regarding owner and researcher opinion respectively obtained some pain relief. Following this some classification, it was observed that at the second return after adjusting the tramadol dosage, pain relieve was achieved in 28 (75,68\%) of the animals the according to the owner and researcher and that an unsuccessful relief in $6(16,21 \%)$ and $7(18,91 \%)$ of patients respectively. When the groups were compared separately it was verified that the group DAINET (dypirona, AINE and tramadol) showed a significant pain relief in relation to the final evaluation, whereas the other two groups (DT - dypirona plus tramadol - and DET dypirona, steroidal anti-inflammatory analgesic and tramadol) presented pain relief only in relation to the final evaluation. Based on the results of pain relief and QV it could be concluded that tramadol was efficient regarding the treatment of moderate to severe pain in dogs with cancer.

Key words: Dogs. Veterinary oncologic (treatment). Analgesia. Opioids. Pain (treatment). 


\section{LISTA DE FIGURAS}

Figura 1 - Correlação entre a avaliação de dor realizada pelo proprietário e pesquisador através da Escala Numérica Verbal (ENV) na consulta

Figura 2 - Correlação entre a avaliação de dor realizada pelo proprietário e pesquisador através da Escala Numérica Verbal (ENV) no primeiro retorno

Figura 3 - Correlação entre a avaliação de dor realizada pelo proprietário e pesquisador através da Escala Numérica Verbal (ENV) no segundo retorno

Figura 4 - Avaliação da dor dos 37 animais realizada através da Escala Numérica Verbal (ENV) nos 3 diferentes momentos de avaliação durante o experimento

Figura 5 - $\quad$ Média dos escores de qualidade de vida dos 37 cães nos diferentes momentos de avaliação durante o tratamento.

Figura 6 - $\quad$ Avaliação da dor dos animais do Grupo I, realizada através da Escala Numérica Verbal (ENV) nos 3 diferentes momentos de avaliação durante o experimento.

Figura 7 - $\quad$ Avaliação da dor dos animais do Grupo II, realizada através da Escala Numérica Verbal (ENV) nos 3 diferentes momentos de avaliação durante o experimento

Figura 8 - $\quad$ Avaliação da dor dos animais do Grupo III, realizada através da Escala Numérica Verbal (ENV) nos 3 diferentes momentos de avaliação durante o experimento.

Tabela 9 - Escore de qualidade de vida dos grupos nos 3 diferentes momentos de avaliação durante o experimento. 


\section{LISTA DE TABELAS}

Tabela 1 - $\quad$ Idade dos 130 cães atendidos durante o estudo........................................... 40

Tabela 2 - $\quad$ Distribuição racial dos 130 cães atendidos durante o estudo...................... 40

Tabela 3 - Localização do tumor primário dos 130 cães atendidos durante o estudo

Tabela 4 - Principais sinais e alterações relatados pelos proprietários dos 130 cães atendidos durante o estudo.

Tabela 5 - Motivos de exclusão, número de animais excluídos e porcentagem do total de animais avaliados (130) e porcentagem do total dos animais excluídos (93).

Tabela 6 - Principais alterações comportamentais relatas pelos proprietários dos 37 cães submetidos no momento de instituição da terapêutica com o tramadol

Tabela 7 - Avaliação da dor realizada pelo proprietário e pesquisador através da Escala Numérica Verbal (ENV) dos 37 cães incluídos para avaliação da terapia analgésica com tramadol nos diferentes momentos de avaliação.

Tabela 8 - Médias do escore de qualidade de vida dos 37 cães incluídos para avaliação da terapia analgésica com tramadol nos diferentes momentos de avaliação.

Tabela 9 - Fármacos empregados para controle de efeitos adversos e sintomas dos 37 cães incluídos no estudo.

Tabela 10 - Associações de fármacos associada a cada grupo e número total de animais em cada

Tabela 11 - Avaliação da dor realizada pelo proprietário e pesquisador através da Escala Numérica Verbal (ENV) e valor do escore de qualidade de vida (QV) dos cães incluídos para avaliação da terapia analgésica com 49 tramadol no Grupo I

Tabela 12 - Avaliação da dor realizada pelo proprietário e pesquisador através da Escala Numérica Verbal (ENV) e valor do escore de qualidade de vida (QV) dos cães incluídos para avaliação da terapia analgésica com tramadol no Grupo II..................................................................................

Tabela 13 - Avaliação da dor realizada pelo proprietário e pesquisador através da Escala Numérica Verbal (ENV) e valor do escore de qualidade de vida (QV) dos cães incluídos para avaliação da terapia analgésica com tramadol no Grupo III 


\section{SUMÁRIO}

1 INTRODUÇÃ

2 REVISÃO DE LITERATURA........................................................... 16

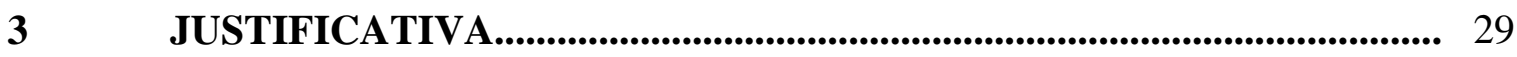

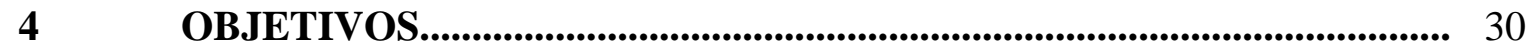

5 MATERIAL E MÉTODOS..................................................................... 31

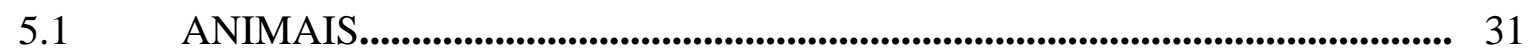

5.2 CRITÉRIOS DE INCLUSÃO NO ESTUDO............................................. 31

5.3 CRITÉRIOS DE EXCLUSÃO PARA ANÁLISE DA TERAPÊUTICA

5.4 DELINEAMENTO DO ESTUDO............................................................ 32

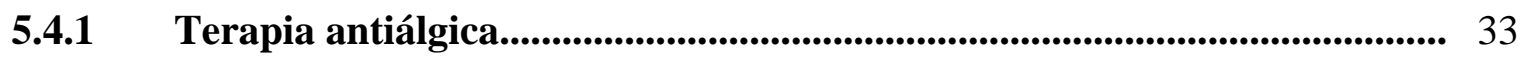

5.4.2 Fármacos analgésicos empregados para o alívio da dor............................ 34

5.4.3 Fármacos adjuvantes empregados durante o tratamento........................ 35

5.4.4 Avaliação da dor e da Qualidade de Vida (QV)......................................... 35

5.4.4.1 Avaliação da dor realizada pelo proprietário ou cuidador e pelo pesquisador............................................................................................................................ 35

5.4.4.2 Avaliação da qualidade de vida (QV).................................................................. 35

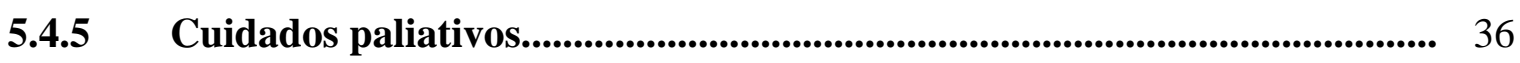

5.4.5.1 Fármacos utilizados para prevenção e tratamento dos efeitos adversos........... 36

5.4.5.2 Manejo de ulcerações tumorais, fraturas patológicas e escaras de

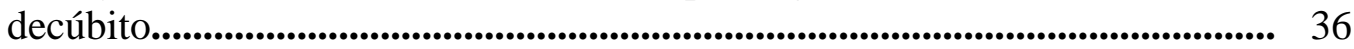

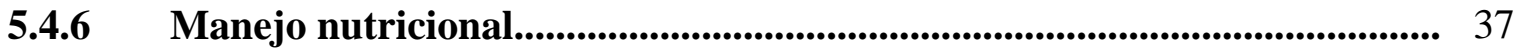

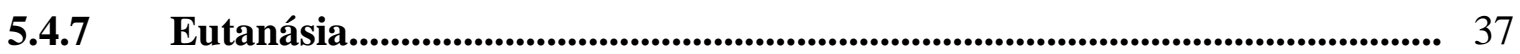

5.5 COLETA DE DADOS DURANTE O ESTUDO......................................... 37

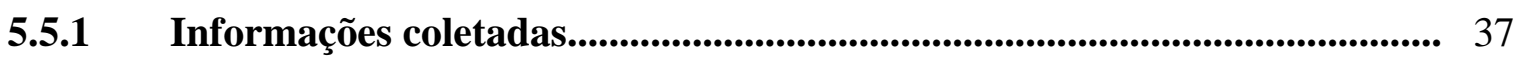


5.5.2 Informações coletadas em relação ao emprego do tramadol 38

5.6 MOMENTOS DE AVALIAÇÃO PARA ANÁLISE DA TERAPÊUTICA...................................................................................... 38

5.7 ANÁLISE ESTATÍSTICA....................................................................... 39

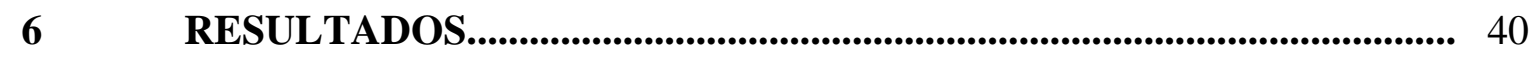

7 DISCUSSÃO

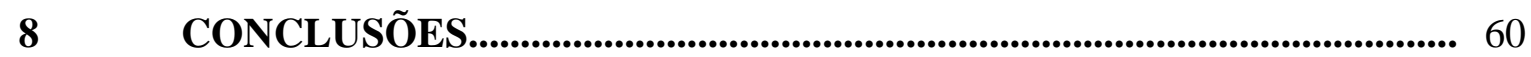

REFERÊNCIAS............................................................................ 61

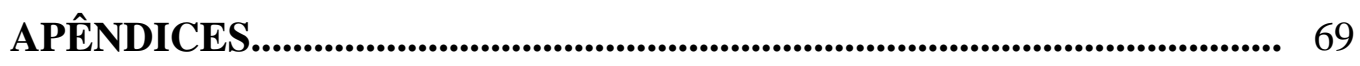

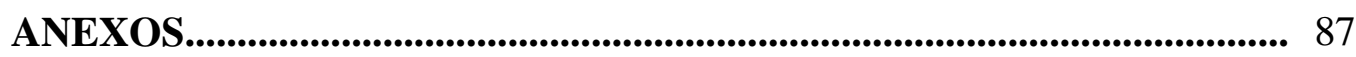




\section{INTRODUÇÃO}

A dor é parte integrante da vida, presente ao longo de todo o ciclo do desenvolvimento desde o nascimento até a morte. Aparece associada a doenças, processos inflamatórios, acidentes e procedimentos médicos ou cirúrgicos e, embora tão desagradável e estressante é essencial para a sobrevivência porque exerce função protetora para o organismo. Entretanto, a intensidade e a freqüência da dor podem exceder suas funções fisiológicas indicadoras e comprometer seriamente a qualidade de vidas dos indivíduos em sofrimento. Essa é, talvez, a mais universal e mais antiga forma conhecida de estresse, que não obstante as tentativas do homem ainda não foi completamente controlada, apesar dos esforços envidados nesse sentido ao longo da história da humanidade (CAMARGO et al., 1994).

A dor oncológica atinge $50 \%$ dos pacientes durante todo o curso da doença. Ao avaliar somente os pacientes na fase avançada, a incidência de dor pode chegar aos $75 \%$ (SCHOELLER, 2002).

A Organização Mundial da Saúde (OMS) reconhece que, mesmo em países com um sistema de saúde mais avançado, 50\% a 80\% dos pacientes são insatisfatoriamente tratados (SCHOELLER, 2002).

Diante da dimensão do problema, a OMS declarou a dor associada ao câncer uma emergência médica mundial, mobilizou esforços e estabeleceu parcerias com várias associações internacionais para promover o Programa de Alívio da Dor Oncológica e Cuidados Paliativos (SCHOELLER, 2002).

Na medicina veterinária são poucos os estudos que avaliam de forma consistente o tratamento da dor oncológica em cães. O presente estudo visa avaliar o efeito da administração do tramadol em cães com dor oncológica objetivando a padronização de esquema terapêutica eficaz e factível. 


\section{REVISÃO DE LITERATURA}

A dor não é apenas uma modalidade sensorial, mas uma experiência. A Associação Internacional para o estudo da Dor (IASP) conceitua a dor como "uma experiência sensorial e emocional desagradável associada à lesão tissular ou potencial, ou descrita em termos desta lesão”. Esta definição reconhece a interpelação entre os aspectos sensoriais fisiológicos, objetivos, da dor e seus componentes subjetivos, emocionais e psicológicos (TEIXEIRA, 2001).

Porém, a percepção da dor não pode ser considerada como um fenômeno sensorial exclusivo dos seres humanos. Enquanto o ser humano tem a capacidade de transformar em palavras o que está sentindo, para o reconhecimento da dor no animal é necessária a observação de seu comportamento(MASTROCINQUE, 2000).

Se na espécie humana é um consenso que ainda existem diversas incógnitas em relação às sensações dolorosas que ainda não foram bem esclarecidas, nos animais as mesmas encontram-se ainda mais obscuras (MASTROCINQUE, 2000).

É crescente, entre os médicos veterinários, a conscientização da necessidade de promover alívio efetivo da dor para pacientes (FANTONI et al., 2000; MASTROCINQUE, 2000) Entretanto, a dor é inadequadamente tratada tanto na medicina veterinária como na humana (FANTONI et al., 2000; KLAMT et al., 1995; PIMENTA et al., 1998). Isto, em parte, reflete a ênfase da medicina no diagnóstico e tratamento dos fatores causais mais que no tratamento sintomático. Outros fatores, como o escasso conhecimento da fisiologia e fisiopatologia da dor, desconhecimento dos benefícios fisiológicos da analgesia, a falta de familiarização com os analgésicos indicados para cães e gatos, desinteresse, desinformação, pouco treinamento de veterinários na avaliação da dor, dificuldades legais e econômicas para a prescrição de analgésicos e o temor de que a utilização de agentes potentes possa levar os animais a quadros de dependência química ou de depressão respiratória e a problemas gastrintestinais, têm contribuído para inaceitável inadequação do controle efetivo da dor (FANTONI et al., 2000; KLAMT et al., 1995; PIMENTA et al., 1998).

Fisiologicamente a dor nociceptiva, especialmente a aguda, é fundamental para a preservação da integridade do indivíduo porque é um sintoma que alerta para a ocorrência de lesões no organismo, já a dor crônica não tem esse valor biológico e é uma importante causa 
de incapacidade, e acarreta alterações de comportamento psicomotor que são prejudiciais ao bem estar físico e mental (OLIVEIRA, 1998; TEIXEIRA, 1999).

O câncer é a maior causa de morbidade e mortalidade em animais de companhia em idade avançada (ALMEIDA, 2002; LESTER; GAYNOR, 2000).

A dor manifesta-se em 30\% a 70\% dos doentes em todos os estágios evolutivos da doença neoplásica; é observada em $20 \%$ a $50 \%$ dos casos quando do diagnóstico e em $70 \%$ a 90\% quando a doença é avançada. É muito intensa em 25\% a 30\% dos doentes. A vivência da dor prolongada freqüentemente resulta em piora das atividades e das condições físicas e funcionais (PIMENTA et al., 1998).

Pacientes com câncer têm múltiplas causas de dor. A maior parte da dor secundária ao câncer pode ser classificada, na origem, como somática, visceral ou neuropática. A dor somática provém de injúrias de tecidos como ossos, músculos, articulações e pele. A dor visceral está ligada à distensão, dano ou inflamação das vísceras e normalmente é mal localizada. O direto envolvimento ou injúria do sistema nervoso central ou periférico pode levar a dor neuropática (LESTER; GAYNOR, 2000).

A dor relacionada ao câncer é, na maioria dos casos constante ou diária. Os episódios são de duração prolongada e geralmente localiza-se em mais de um local. A duração do quadro doloroso está geralmente relacionada ao estágio da doença, podendo variar entre dias e anos, apresentando ainda períodos de remissão. A dor no paciente com câncer é descrita como moderada em cerca $30 \%$ a $60 \%$ dos casos e é muito intensa em 17\% a 40\% (PIMENTA et al., 1998).

O tratamento da dor oncológica na medicina humana é, entretanto ainda inadequado em países evoluídos socioculturalmente (TEIXEIRA, 2001). Essa situação é ainda mais dramática nos animais, onde muitos são assistidos em estágios avançados da doença, quando a cura é impossível, e o controle da dor e de outros sintomas se torna a razão da assistência (TEIXEIRA, 2001; TEIXEIRA, 2001) .

A causa da dor também tem sido pesquisada ao longo do tempo. Ela já foi considerada um castigo mandado por deuses ofendidos, já foi atribuída a presença de maus espíritos e à perda de substâncias vitais ao organismo (CAMARGO et al., 1994; FANTONI; MASTROCINQUE, 2002). Esteve presente, desde a Antiguidade, no pensamento de grandes filósofos e médicos como Aristóteles e Galeno. A primeira grande influência foi de Descartes que, em 1664, descreveu a dor como uma sensação percebida no cérebro, resultante de uma estimulação dos nervos sensoriais(CAMARGO et al., 1994). Porém, em 1895, Strong atribuiu 
igual importância aos aspectos psicológicos e orgânicos na percepção da dor. A IASP tem o objetivo de integrar as múltiplas disciplinas visando o entendimento da dor, entretanto, os estudos realizados são ainda insuficientes e colecionam muitas questões sem resposta sobre as diversas causas, a percepção subjetiva e as muitas técnicas de tratamento da dor (CAMARGO et al., 1994).

A compreensão dos mecanismos fisiológicos da dor é primordial para que haja intervenção terapêutica adequada. O primeiro passo na seqüência dos eventos que originam o fenômeno sensitivo-doloroso é a transformação dos estímulos ambientais em potencial de ação que, das fibras nervosas periféricas, são transferidos para o sistema nervoso central (TEIXEIRA, 2001).

Em condições normais, a informação sensorial é captada pelas estruturas do sistema nervoso periférico e transmitida para as unidades do sistema nervoso central, onde é decodificada e interpretada (TEIXEIRA, 1999).

Os nociceptores são terminações livres das fibras nervosas aferentes primárias que convertem estímulos químicos, mecânicos ou térmicos em impulsos nervosos que são transmitidos ao sistema nervoso central. Normalmente, a estimulação nociceptiva periférica ativa os nociceptores e desencadeia reação de defesa com liberação de mediadores químicos (TEIXEIRA, 2001).

Existem tipos de fibras que carreiam estes estímulos: fibras $\mathrm{A} \alpha$, A $\delta$ e fibras C. As fibras mielinizadas (A $\alpha$ e $A \delta$ ) têm freqüência de condução mais rápida. Elas sinalizam estimulações químicas ou mecânicas intensas. As fibras C, não mielinizadas, são fibras aferentes conhecidas como nociceptores polimodais (C-PMN), pois respondem a impulsos mecânicos, térmicos e químicos. Elas têm menor diâmetro e realizam condução lenta. A maior parte das fibras A $\delta$ termina na lâmina I, também chamada zona marginal. As fibras C seguem para a lâmina superficial dorsal na medula espinhal (substância gelatinosa) (TEIXEIRA, 2001).

Quando ocorre trauma tecidual, diferentes substâncias químicas são liberadas. Estas, denominadas de mediadores promovem vasodilatação com extravasamento de proteínas plasmáticas e recrutamento de células inflamatórias. Dentre os diversos mediadores, pode-se destacar: íons hidrogênio, norepinefrina, bradicinina, histamina, íons potássio, citocinas, serotonina, óxido nítrico e produtos do metabolismo do ácido aracdônico (CARVALHO; LEMONICA, 1998; KADAR, 1989; TASAKA, 1999). Estes mediadores estão envolvidos em 
diferentes processos podendo participar ativamente na perpetuação do processo doloroso, sua intensificação e cronificação (CARVALHO; LEMONICA, 1998).

No corno dorsal, a comunicação entre os neurônios é mediada por aminoácidos excitatórios e inibitórios e por neuropeptídeos (substância P, neurotensina, peptídeo geneticamente ligado a calcitonina, colecistoquinina) que são produzidos, estocados e liberados nos terminais das fibras nervosas aferentes. Os impulsos nociceptivos do corno dorsal convergem para centros supraespinhais. O trato espinotalâmico é a mais proeminente via nociceptiva da medula espinhal (LAMONT, 2000).

Os nociceptores são, particularmente, numerosos na pele, peritônio, pleura, periósteo, cápsulas articulares, parede arterial, músculos e tendões, embora sua distribuição varie dependendo da espécie (LAMONT, 2000; TEIXEIRA, 2001).

O impulso nociceptivo gerado por esses receptores é processado em varias lâminas da medula espinhal, sendo os aspectos físicos da dor atribuídos as vias aferentes do tálamo que chegam ao córtex cerebral e as vias aferentes ao sistema límbico relacionadas aos componentes emocionais da dor (CARROL, 1999; TEIXEIRA, 2001).

Além da modulação ascendente há também a modulação da dor espinhal como propõe a “Teoria da Comporta” descrita por Melzac e Wall, em 1965, segundo a qual a substância gelatinosa e áreas do sistema nervoso central podem bloquear a transferência das informações entre os aferentes e os neurônios da medula espinhal (CAMARGO et al., 1994; CARROL, 1999; TEIXEIRA, 2001).

A dificuldade de definir dor em animais está no fato desta ser uma análise subjetiva da atividade do sistema nervoso central. O estudo do comportamento é crucial para o processo de avaliação da dor e desconforto em animais. As respostas comportamentais diante da dor e de outras causas de estresse são resultados da interação entre indivíduo e meio, e são afetados por muitos fatores, tais como: sexo, raça, idade, origem da dor e doença coexistente (HANSEN, 1997).

Dentre as alterações comportamentais exibidas por animais que apresentam dor podese citar: alterações na aparência do animal, que se mostra com pêlos eriçados, sem brilho, com descarga nasal e/ou ocular, exibindo padrão respiratório alterado. $\mathrm{O}$ animal pode ainda estar nervoso, agitado ou agressivo. Há diminuição na sua atividade e relutância em se movimentar, ou ao se movimentar o faz vagarosamente e protegendo a área dolorida. A diminuição na ingestão de água e comida é grave conseqüência associada ao estresse da dor, e levam à 
diminuição do volume de fezes e urina, perda de peso e até desidratação (HASKINS, 1987; MORTON; GRIFFITHIS, 1985).

A mesma dificuldade encontrada pelos médicos veterinários para a avaliação da dor nos animais, é enfrentada pelos pediatras, enfermeiras e anestesistas na avaliação da dor em neonatos e crianças que ainda não conseguem se comunicar verbalmente (YAZBEK; FANTONI, 2005). Em pediatria o comportamento é uma medida útil e um indicador de dor em crianças. A dor influencia a percepção da criança e focaliza sua atenção para o local de onde se originou o estímulo doloroso(OKADA et al., 2001; TEIXEIRA; PIMENTA, 2001). Entretanto, a maioria das medidas comportamentais sobre dor foram desenvolvidas e validadas para condições de dor aguda ou dor pós-operatória (OKADA et al., 2001) fato que também ocorre na Medicina Veterinária. Alterações nos parâmetros fisiológicos como aumento da freqüência cardíaca, respiratória, sudorese da pele entre outros e o choro são utilizados quase que exclusivamente para avaliar a dor aguda. A reação à dor crônica é caracterizada pelo isolamento prolongado e por manifestações comportamentais semelhantes ao da depressão. A maioria das escalas quantitativas que visam analisar a intensidade da dor utiliza métodos de auto-relato que incluem palavras, cores, números, termômetros, associação com frutas, escalas visuais e analógicas e de face. As entrevistas sobre qualidade e intensidade da dor são aplicáveis essencialmente em crianças com mais de 5 anos de idade. A compreensão e interpretação da dor em crianças com menos de 4 anos de idade ainda é um dos maiores desafios para pesquisadores e clínicos (OKADA et al., 2001; TEIXEIRA; PIMENTA, 2001).

A mesma dificuldade é encontrada na Medicina Veterinária. Atualmente existem várias escalas para mensuração de dor aguda em cães e gatos, mas a maior dificuldade encontrada é como mensurar e monitorar a dor crônica nos animais de companhia (YAZBEK; 2005).

Nos estudos recentes, onde se fez necessário a quantificação da dor em animais, observa-se o uso de escalas utilizadas para a mensuração da dor em humanos adaptadas para animais (ALMEIDA, 2002; MASTROCINQUE, 2000).

A Escala Analógica Visual (VAS), amplamente utilizada, é uma linha com $10 \mathrm{~cm}$ de comprimento que apresenta em uma extremidade o conceito "ausência de dor" (zero) e na outra "pior dor imaginável” (dez). O paciente marca com uma caneta onde se localiza a dor (ALMEIDA, 2002; FANTONI; MASTROCINQUE, 2002; MASTROCINQUE, 2000). Esta 
escala pode ser fornecida ao proprietário do animal ou pode ser utilizada por médicos veterinários para monitorar a terapia analgésica (ALMEIDA, 2002).

Outro tipo de escala utilizada em humanos adultos é a Escala Numérica, onde são colocados números de 1 a 10 para que o paciente marque a intensidade da sua dor (SOUSA, 2002).

São utilizadas também as Escalas Numéricas Verbais, onde se pede para o paciente dar uma nota de zero (ausência de dor) a dez (pior dor imaginável) para a dor, e a Escala Descritiva Verbal onde a dor é classificada em ausente, leve, moderada e intensa (SOUSA, 2002).

O alívio da dor é essencial antes, durante e após o tratamento oncológico, mesmo quando a doença se encontra em fase avançada. Para a instituição do tratamento é necessária a identificação do tipo de dor, a localização correta, o estado físico que o paciente se encontra, a fase do tratamento, as limitações e os riscos dos procedimentos. Há vários modos de tratar a dor no doente com câncer. O tratamento consiste no uso simultâneo ou sucessivo de métodos adaptados às necessidades de cada doente, tendo como base que os procedimentos menos invasivos são preferíveis (SAKATA, 2001).

O controle farmacológico da dor foi introduzido nos últimos 20 anos sob a orientação da Organização Mundial da Saúde (OMS), e os medicamentos mais utilizados são os analgésicos opióides, analgésicos antiinflamatórios e os fármacos adjuvantes, como os antidepressivos e os anticonvulsivantes (GIUBLIN, 2002).

O uso de analgésicos deve ser iniciado assim que o diagnóstico da presença da dor for estabelecido, não se esperando que o paciente apresente dor intensa para a prescrição do medicamento (GIUBLIN, 2002; TEIXEIRA et al., 1999).

O tratamento é iniciado com analgésicos antiinflamatórios. Se a dor não for controlada é acrescido um opióide fraco, e quando a dor ainda persistir, usa-se um opióide forte. O uso de agentes adjuvantes se faz necessário em muitos pacientes (GIUBLIN, 2002). Esta proposta de escalonar a medicação anti-álgica de acordo com o grau de dor também partiu da Organização Mundial da Saúde no sentido de padronizar a terapêutica, facilitando a comparação de resultados e técnicas.

Os princípios básicos para o uso eficaz destas medicações são: administração preferencialmente pela via oral; respeito ao horário estipulado; dose calculada de maneira individual e freqüente reavaliação da dor (GIUBLIN, 2002). 
Os analgésicos antiinflamatórios não esteroidais (AINEs) são o grupo de fármacos indicados para o tratamento da dor de intensidade de leve a moderada. Apresentam atividade analgésica, antipirética e antiinflamatória podendo ser associados aos opióides e os fármacos adjuvantes (GIUBLIN, 2002).

Os AINEs são agentes não narcóticos que inibem as enzimas que participam do metabolismo do ácido aracdônico e da formação de eicosanóides, como os prostanóides (prostaglandinas, prostaciclina, tromboxano) e leucotrienos. As prostaglandinas, particularmente $\mathrm{PGE}_{2}$ e $\mathrm{PGI}_{2}$, tem um papel na produção de estímulos nocivos na periferia, sensibilizando os receptores e as terminações neuronais aferentes à ação de bradicinina, histamina e outros compostos liberados durante o processo inflamatório. As prostaglandinas, graças a sua ação sobre o sistema nervoso central, também facilitam a transmissão de estímulos nocivos que são transmitidos para a medula espinhal e, posteriormente, para centros superiores. Isto ocorre particularmente durante a dor pós-operatória grave e na dor crônica. Assim, os medicamentos que inibem a produção de prostaglandinas, inibindo a cicloxigenase (COX), produzem efeitos analgésicos por meio de ações centrais e periféricas (LASCELLES, 1999).

Para a obtenção de melhores resultados, com mínima incidência de efeitos adversos, alguns cuidados devem ser observados quando se pretende administrar um AINE. A dose deve ser calculada adequadamente para a espécie animal a ser utilizada, respeitar o intervalo de administração, fazer uso de medicação testada e aprovada para administração em animais (FANTONI et al., 2000).

O uso de AINE é contra-indicado para pacientes nefropatas, hepatopatas, trombocitopênicos, hipertensos arteriais, doentes com insuficiência cardíaca congestiva, desidratados, hipotensos e que estejam sendo medicados com fármacos que possam causar nefrotoxicidade e disfunção plaquetária (POSSO et al., 1994). Todos os pacientes com câncer que estiverem sendo medicados com AINE devem ser cuidadosamente monitorados em relação a sangramento gastrointestinal e nefrotoxicidade durante a quimioterapia (GIUBLIN, 2002). Cumpre salientar que o risco de toxicidade aumenta com a idade, tendo-se observado que os eventos adversos devido ao uso de AINE resultam em aumento da mortalidade em pacientes idosos (POSSO et al., 1994), que são grande maioria quando se trata de pacientes portadores de câncer.

Na medicina humana, os AINE mais prescritos são: diclofenaco, tenoxicam, cetoprofeno, piroxicam, meloxicam, celecoxib, rofecoxib e o flurbiprofeno (SAKATA, 2001). 
Dos AINEs citados acima, só o cetoprofeno e o meloxicam são amplamente utilizados na Medicina Veterinária. O diclofenaco, piroxicam, tenoxicam e o flurbiprofeno são contraindicados para uso em cães e gatos e o celecoxib e o rofecoxib ainda não foram investigados na Medicina Veterinária.

O meloxicam é um derivado oxicano, é um potente inibidor da síntese de prostaglandinas sendo desta maneira antiinflamatório, analgésico e antipirético. O meloxicam tem ação preferencial na inibição da COX-2 e tem pouca ação inibitória da COX-1 (ENGELHARD; et al., 1996a, 1996b). A administração pré-operatória de meloxicam é aprovada na Europa e no Canadá para o controle da dor pós-operatório e também está aprovado seu emprego para o tratamento da dor aguda e crônica em cães (BROWN, 1989; DENEUCHE et al., 2004).

O carprofeno é amplamente utilizado para o controle da dor nas doenças degenerativas articulares, displasia coxofemoral e no controle da dor aguda pós-operatória em cães (MATHEWS, 1995, 2000). Este geralmente é considerado bem tolerado em cães (RAEKALLIO et al., 2006). A dose indicada para uso em cães é 2,2 mgkg a cada 12 horas pela via oral (GAYNOR, 2001; MATHEWS, 2000).

A dipirona não possui efeito antiinflamatório, mas é classificada como tal. Possui potente ação analgésica, é muito utilizada para o tratamento da dor aguda e amplamente utilizada em muitos países, como por exemplo, na Espanha, para o tratamento da dor oncológica no homem (RODRÍGUEZ et al., 1994). No Canadá e na Europa a dipirona é liberada para uso em cães e gatos (MATHEWS, 1995). Rodriguez et al. (1994), demonstraram que dipirona na dose de $2 \mathrm{~g}$ a cada 8 horas possui a mesma eficácia analgésica comparada a 10mg de morfina a cada 4 horas no homem com câncer. No Brasil, a dipirona é muito utilizada no tratamento da dor aguda pós-operatória e como auxiliar na terapia analgésica em pacientes com câncer (SAKATA, 2004). Uma das grandes vantagens desse agente é o fato de causar pouquíssimos efeitos colaterais renais ou gastrintestinais. É indicada para o tratamento da dor leve e como antipirético (PIMENTA et al., 1998; TEIXEIRA; VALLE, 2001). Não há, até o momento, nenhum trabalho publicado na literatura Veterinária utilizando a dipirona como auxiliar no tratamento da dor crônica em cães e gatos. A dose preconizada para cães é de $25 \mathrm{mgkg}$ a cada 6 a 8 horas pela via oral, intramuscular ou intravenosa (FANTONI; MASTROCINQUE, 2002; MATHEWS, 2000). 
Os corticosteróides, dentre eles a dexametasona e a prednisona, são utilizados no tratamento da dor associada a lesões traumáticas, inflamatórias e neoplásicas do sistema nervoso periférico e do SNC e a dor associada a doenças inflamatórias e neoplásicas sistêmicas com presença de metástase óssea (TEIXEIRA, 1999). São muito eficazes no tratamento da dor causada por tumores ósseos. Promovem estabilização da membrana neural, exercem ação antiinflamatória, reduzem os níveis dos mediadores que ativam e sensibilizam os nociceptores, reduzem a atividade ectópica em locais de lesão neural, reduzem o edema, causam euforia e bem-estar e estimulam o apetite (SAKATA, 2001; TEIXEIRA, 1999). O agente mais utilizado é a dexametasona (SAKATA, 2001).

Dentre os analgésicos utilizados em medicina veterinária, os derivados do ópio têm sido uma alternativa bastante viável devido à sua eficiência no que diz respeito ao controle da dor e à possibilidade de causarem poucos efeitos adversos (PAPICH, 1997).

Produzem analgesia por mimetizar a ação dos opióides endógenos sobre os receptores específicos (GIUBLIN, 2002).

Os opióides endógenos modulam a transmissão dolorosa através de um sistema antinociceptivo endógeno. Existem três famílias de opióides peptídeos que fazem parte deste sistema. As encefalinas que são derivadas da proencefaina $A$, a $\beta$-endorfina que é derivada do pró-opiomelanocortina e é liberada juntamente com o hormônio ACTH pela glândula pituitária, e é considerado o opióide endógeno mais potente. A dimorfina que é originada da prodinorfina, porém com menor efeito analgésico (GIUBLIN, 2002).

Os efeitos adversos, quando ocorrem, podem ser revertidos, o que é obtido mediante a administração de opióides antagonistas como a naloxona. O fato de não promoverem efeitos adversos graves permite que os opióides possam ser utilizados mesmo em altas doses, quando necessário (LASCELLES; WATERMAN, 1997; PAPICH, 1997).

Os efeitos desencadeados pelos opióides são mediados pela ligação a receptores específicos. Quatro tipos de receptores corpóreos para opióides são descritos. Também há presença destes receptores fora do SNC, como por exemplo, no trato gastrintestinal. O receptor mi $(\mu)$ é responsável por euforia, sedação, analgesia e depressão respiratória. O

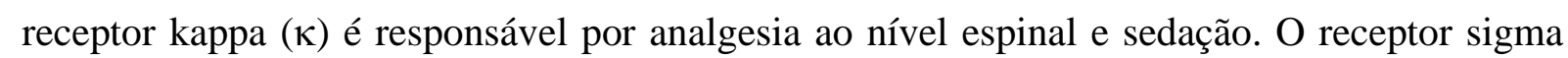
$(\sigma)$ produz disforia, excitação, insônia e efeitos alucinógenos. O receptor delta $(\delta)$ ainda não foi bem descrito. No sistema nervoso central, os opióides produzem analgesia, euforia, sedação e excitação, sendo que os efeitos de excitação e disforia são mais observados quando 
é feita a administração em animais saudáveis, e são menos comuns em animais com dor. O efeito de euforia, característico dos opióides agonistas para o receptor $\mu$, auxiliam na diminuição da ansiedade e estresse em animais que estão em ambientes estranhos (PAPICH, 1997).

Os opióides são os medicamentos de escolha para pacientes com dor de grau moderado e intenso, podendo ser associados a analgésicos antiinflamatórios. Essa associação possibilita a diminuição da dose de opióides e uma somação de efeitos por apresentarem mecanismos de ação diferentes e atuarem, portanto em diferentes locais (GIUBLIN, 2002).

Novos agentes como o tramadol parecem apresentar eficácia similar e menos efeitos adversos que os analgésicos convencionais (TEIXEIRA et al., 1999).

O tramadol é um derivado 1-(m-metioxifenil)-2-(dimetilaminometil)-ciclohexano-1-ol (tramadol), classificado como analgésico morfínico e utilizado desde 1977, na Europa. Eleva o limiar da dor em animais de experimentação e em seres humanos. Apresenta atividade béquica (antitussígena) equivalente a $50 \%$ da atividade da codeína. Não apresenta efeito antitérmico. Reduz os níveis de $\beta$-endorfina circulante em condições de dor pós-operatória (TEIXEIRA et al., 1999). Parece atuar em várias unidades modulatórias do sistema nervoso central, incluindo a medula e a formação reticular do tronco encefálico. Apresenta moderada afinidade pelos receptores morfínicos $\mu$ e fraca afinidade pelos receptores $\kappa$ e $\delta$. Seu efeito é reduzido parcialmente com o uso de nalorfina e naloxona. Além de ligar-se aos receptores morfínicos, bloqueia a recaptação de serotonina e noradrenalina, possivelmente nas vias supressoras descendentes que, do tronco encefálico, alcançam o corno posterior da medula espinhal (FANTONI ; MASTROCINQUE, 2002; RADBRUCH et al., 1996; REIG, 2002; TEIXEIRA et al., 1999). O tramadol tem sua açãoagonista em receptores opiáceos é considerada 10 vezes menor que a ação da codeína, 1000 quando comparado com a metadona e 6000 em relação a da morfina (MIRANDA; PINARDI, 1998). A combinação opióide e não opióide mecanismos de ação resulta em sinergismo que potencializa seu efeito analgésico (RADBRUCH et al., 1996).

Seu metabólito, o O-desmetil-tramadol apresenta maior afinidade pelos receptores $\mu$ e maior potência analgésica que o agente primário. Não apresenta efeito antagonista em relação à morfina ou o faz em pequena magnitude. Apresenta-se como isômeros cis e trans, ambos com estrutura arquitetônica molecular semelhante á morfina. O isômero trans é mais analgésico que o cis. A forma trans por via subcutânea apresenta um terço da potência 
analgésica da morfina. A meia-vida de eliminação é cerca de quatro horas. A duração da ação chega a 14 horas com média de três a seis horas no homem (TEIXEIRA et al., 1999).

Quando comparado com a morfina de liberação prolongada, os efeitos analgésicos proporcionados pelo tramadol são superiores, com poucos efeitos adversos e tolerabilidade excepcionais (REIG, 2002). O tramadol é metabolizado pelo fígado e excretado pelo rim (RADBRUCH et al., 1996).

Em estudo aberto, realizado por Teixeira et al. (1999), com 1355 pacientes, foi avaliada a segurança do tramadol, por 225 médicos de várias especialidades, sendo que na maioria das vezes (94\%), a dor foi quantificada de moderada à intensa e mais de $40 \%$ dos pacientes haviam sido previamente medicados com outros analgésicos. Nesse estudo a duração do tratamento foi superior a três semanas em grande número de pacientes com dor resultante do câncer e anormalidades do aparelho locomotor, condições estas em que, habitualmente, há necessidade de analgesia prolongada. Ocorreu melhora significante ou alívio da dor em 82,5\% dos casos.

Em estudo realizado por Osipova et al. (1991) envolvendo 98 pacientes com câncer, com dor considerada de grau moderado em $11 \%$ dos pacientes e $89 \%$ com dor intensa, relatou excelente ou bom alívio da dor com o emprego de tramadol pela via oral.

O tramadol é um agente bem tolerado. Os efeitos adversos manifestados em humanos são náuseas, sonolência e tonturas, os quais alcançam 65\% dos efeitos adversos observados; em algumas ocasiões foram citadas outras complicações como a fadiga, sedação, dispnéia, cefaléia, sudorese, sialosquese, emese, disúria, extra-sístoles, palpitações, ansiedade, alterações da percepção do corpo, alucinações e hiperemia cutânea (REIG, 2002; TEIXEIRA et al., 1999).

Experimentos realizados em animais não relataram tolerância ou dependência induzida pelo uso de tramadol por tempo prolongado em ratos (RADBRUCH et al., 1996).

Os incrementos das doses do tramadol de liberação rápida para o controle da dor devem ser paulatinas, sendo realizado com intervalo mínimo de 24 horas (BENITEZ DEL ROSARIO, 2002).

No que tange ao emprego de tramadol em cães e gatos, ainda há escassez de estudos que comprovem sua eficácia nestas espéscies. Yazbek et al. (1999), em estudo comparando a analgesia profilática deste agente com aquela produzida pelo antiinflamatório não esteroidal flunexin-meglumine, em cães que sofreram intervenção ortopédicas, verificaram resultado bastante satisfatório em relação ao controle da dor no grupo tratado com tramadol, o qual 
apresentou menores escores de dor, avaliada pela escala analógica visual. O grupo tratado com tramadol entretanto apresentou maior grau de sedação.

Ao comparar a utilização profilática do tramadol com morfina, em cadelas, para controle da dor após ovariosalphingohisterectomia, Mastrocinque e Fantoni (2003) puderam observar que ambos os agentes produziram analgesia satisfatória, redução dos requerimentos de isofluorano no período trans-operatório e baixos escores de sedação ou outros efeitos adversos nos períodos trans e pós-operatório.

Os adjuvantes são representados por fármacos originalmente utilizados para outras finalidades que não o tratamento da dor, mas que atuam melhorando o rendimento do tratamento analgésico, o desempenho afetivo-motivacional, o apetite, e o sono dos doentes. São representados por corticosteróides, antidepressivos, neurolépticos, ansiolíticos, anticonvulsivantes, anfetaminas, moduladores adrenérgicos, anestésicos locais, inibidores da reabsorção óssea, inibidores dos receptores NMDA, dentre outros (TEIXEIRA, 1999).

Os antidepressivos tricíclicos têm papel importante na analgesia de pacientes com dor de origem neoplásica, nos casos de dores mistas com componente neuropático. O antidepressivo mais utilizado tem sido a amitriptilina e que conta com maior número de trabalhos publicados em literatura médica nacional e internacional, com trabalhos controlados que evidenciam o seu poder analgésico (TEIXEIRA, 1999). Os antidepressivos (amitriptilina, imipramina, fluoxetina, sertralina) inibem a recaptação de serotonina e noradrenalina nas sinapses, ativam as vias descendentes opioidérgicas, inibem os receptores NMDA e bloqueiam os canais de sódio. São usados no tratamento da dor neuropática para potencializar o efeito dos opióides, para reduzir a ansiedade e a depressão e para melhorar o sono (SAKATA, 2001). Entre os efeitos terapêuticos resultantes de sua aplicação pode-se citar regulação do sono e do apetite, melhora da disposição física e psíquica e da dor (JALES JÚNIOR; TEIXEIRA, 2003). Os efeitos adversos mais comuns são sedação, constipação e hipotensão ortostática no homem (SAKATA, 2001). A amitriptilina è o antidepressivo tricíclico mais utilizado no tratamento da dor, especialmente no doente ansioso, deprimido e agitado (JALES JÚNIOR; TEIXEIRA, 2003), na medicina humana.

Os neurolépticos atuam central e perifericamente e exercem ação ansiolítica e relaxante muscular. Ativam as vias inibitórias descendentes e interagem sinergicamente com os receptores opióides, inibem a neurotransmissão de dopamina, noradrenalina, serotonina e histamina. São indicados no tratamento da dor neuropática, controle da dispnéia, da agitação e vômitos e para sedação de doentes na fase terminal de evolução da doença oncológica. No 
homem os mais utilizados são a clorpromazina e o haloperidol. Como efeitos adversos são citados a sedação, agranulocitose, xerostomia, hipotensão ortostática e leucopenia (SAKATA, 2001).

O controle da dor é parte essencial de qualquer protocolo para o tratamento do câncer. A contínua avaliação da dor e do sucesso do tratamento instituído é necessário para a realização do controle da dor oncológica. O não alivio da dor leva ao sofrimento, estresse, ansiedade e diminui a qualidade de vida (LESTER; GAYNOR, 2000). 


\section{JUSTIFICATIVA}

A literatura veterinária é escassa no que diz respeito a estudos que avaliem ou sugiram terapêuticas analgésicas em relação ao tratamento de cães portadores de dor moderada decorrente de câncer. Os poucos estudos existentes avaliam apenas a terapêutica para o tratamento da dor aguda. Sendo assim, faz-se necessária avaliação pormenorizada de terapêutica específica para o tratamento da dor crônica em pacientes com câncer, tendo em vista a alta incidência desta afecção em cães. 


\section{OBJETIVOS}

Com o intuito de controlar a dor e conferir melhor qualidade de vida aos animais portadores de câncer este estudo teve como objetivo principal avaliar o emprego do tramadol em cães com dor oncológica.

Para tanto objetivou-se:

- Avaliar a eficácia, efetividade e segurança do uso do tramadol para o controle da dor de intensidade moderada à intensa em cães portadores de dor oncológica.

- Estabelecer o melhor esquema terapêutico no que diz respeito às doses e intervalos de administração.

- Avaliar a incidência de efeitos adversos e a possibilidade de seu controle com tratamento paliativo. 


\section{MATERIAL E MÉTODOS}

O presente estudo foi aprovado pela Comissão de Bioética da Faculdade de Medicina Veterinária e Zootecnia da Universidade de São Paulo. Os proprietários foram previamente informados a cerca do objetivo do tratamento proposto.

\subsection{ANIMAIS}

Foram estudados animais da espécie canina, machos ou fêmeas, de diferentes raças e idades, encaminhados ao Grupo de Dor e Cuidados Paliativos do Serviço de Anestesia do Hospital Veterinário da Faculdade de Medicina Veterinária e Zootecnia da Universidade de São Paulo, no período de agosto de 2004 a março de 2006.

\subsection{CRITÉRIOS DE INCLUSÃO NO ESTUDO}

Foram critérios para inclusão neste estudo:

- cães com diagnóstico de câncer, baseado nos resultados obtidos através do exame clínico e exames complementares tais como, radiografia, ultra-sonografia, tomografia, citologia ou histopatológico;

- presença de dor de grau moderado (> de acordo com o VAS) não responsiva a tratamento com dipirona e ou antiinflamatórios esteroidais ou não esteroidais;

- cães que permanecessem no mínimo 15 dias em tratamento com tramadol;

- o custo do tratamento deveria ser financiado pelo proprietário do animal. 


\subsection{CRITÉRIOS DE EXCLUSÃO PARA ANÁLISE DA TERAPÊUTICA ANALGÉSICA}

Foram excluídos do estudo cães agressivos que não permitiram a avaliação do pesquisador; cães que não foram medicados corretamente pelo proprietário; cães de proprietários com impossibilidade em retornar ao Grupo de Dor para acompanhamento semanal, com grau de escolaridade insuficiente para compreender a avaliação da dor e o questionário de qualidade de vida e que não fossem familiarizados com os hábitos e comportamento do animal em estudo; cães previamente medicados com opióides prescritos pelo clínico responsável.

\subsection{DELINEAMENTO DO ESTUDO}

Após a realização da avaliação física, quantificação e localização do quadro álgico, os animais foram submetidos ao tratamento analgésico de acordo com a terapia proposta pela Organização Mundial de Saúde (OMS) para o controle da dor oncológica na qual a presença de dor moderada deve ser tratada com opióides fracos asssociados ou não a antiinflamatórios, neste estudo priorizou-se o emprego do tramadol para animais com dor de grau moderada à intensa.

No primeiro momento, todos os animais que apresentaram dor, foram medicados com dipirona e ou antiinflamatório esteroidal ou não esteroidal; após 10 dias os animais foram reavaliados e aqueles que apresentaram dor de grau moderada a intensa ( $>4$ de acordo com 0 VAS) foram tratados com tramadol na dose de $2 \mathrm{mg} / \mathrm{Kg}$ a cada 8 horas.

Os cães foram avaliados semanalmente pelo mesmo veterinário (pesquisador) e também pelo mesmo cuidador ou proprietário. Exames complementares e procedimentos invasivos só foram realizados quando o resultado fosse imprescindível para direcionar a conduta terapêutica. Animais diabéticos, cardiopatas, nefropatas, hepatopatas, epiléticos, e portadores de qualquer outra doença tiveram as medicações mantidas de acordo com o tratamento prescrito pelo clínico responsável pelo caso. Todos os proprietários possuíam contato telefônico direto com o pesquisador para emergências e dúvidas em relação ao tratamento. 


\subsubsection{Terapia antiálgica}

Levando-se em conta as diferentes etiologias e quadros clínicos apresentados pelos pacientes, e seguindo-se as orientações OMS, os animais que receberam tramadol já estavam sendo anteriormente medicados com dipirona e ou antiinflamatórios esteroidais ou não esteroidais.

Os animais foram distribuídos em 3 grupos:

- Grupo DT: Animais medicados com dipirona e tramadol;

- Grupo DAINET: Animais medicados com dipirona associada a antiinflamatório não esteroidal (carprofeno ou meloxicam) e tramadol;

- Grupo DET: Animais medicados com dipirona associada a antiinflamatório esteroidal (prednisona) e tramadol.

A distribuição dos animais nos grupos acima citados foi realizada de acordo com o protocolo terapêutico ao qual o animal estava submetido no momento da primeira consulta. Todos os animais foram submetidos à avaliação previa do pesquisador (veterinário), antes de ser incluído em um dos grupos.

A via de administração preferencial foi A via oral.

Todos os proprietários receberam um quadro com os horários dos medicamentos para impedir o esquecimento e trocas dos horários da administração dos fármacos (Apêndice A).

Vale ainda dizer que o controle para verificação da eficácia do tratamento foi a primeira avaliação realizada da intensidade da dor durante a consulta, sendo a terapêutica considerada ineficaz nos casos em que não houve alterações que indicassem diminuição da intensidade da dor apresentada pelo paciente e/ou quando ENV > ou igual a 4.

Os animais foram comparados dentro dos grupos citados e em conjunto com o intuito de confirmar ou descartar a hipótese de eficácia e segurança no emprego do tramadol para tratamento da dor oncológica.

A eficácia do tratamento realizado com o tramadol foi classificada em três categorias: alívio da dor (ENVinicial > ENVfinal e ENVfinal < 4), melhora insatisfatória (ENVinicial > ENVfinal e ENVfinal > 4) e ausência de melhora (ENVinicial $\leq$ ENVfinal) (TEIXEIRA et al, 1999) 


\subsubsection{Fármacos analgésicos empregados para o alívio da dor}

Como delineado acima nos critérios de inclusão, os animais admitidos neste estudo apresentavam dor de intensidade moderada à intensa mesmo quando já medicados com dipirona associada ou não a antiinflamatórios não esteroidais ou esteroidais há mais de 10 (dez) dias. Neste momento era instituído a terapêutica com o uso de tramadol com dose inicial de $2 \mathrm{mg} / \mathrm{Kg}$ a cada 8 (oito) horas, sendo que os incrementos das doses foram realizados somente após 72 horas do início da terapia onde não se havia alcançado o controle efetivo da dor (VAS>4) (BENITEZ DEL ROSARIO, 2002). Os animais foram reavaliados a cada 7 (sete) dias após o início da terapia.

A instituição da presente terapia é baseada nos princípios descritos por GIUBLIN, 2002, segundo o qual a terapia deve ser realizada preferencialmente pela via oral.

Na ocorrência de efeitos adversos, como nos casos de sonolência e de excitação, a dose administrada sofreu uma redução de 30\%, quando possível, com o intuito de debelar estes efeitos adversos, mantendo o efeito analgésico proporcionado pelo fármaco utilizado. Na persistência dos efeitos adversos o tramadol seria descontinuado.

No presente estudo, foram utilizados os seguintes fármacos para o controle da dor (Quadro 1):

\begin{tabular}{|cccc|}
\hline FÁRMACOS & DOSE (mgkg) & VIA & FREQÜÊNCIA \\
& & & \\
\hline Dipirona & 25 & Oral & a cada 8 horas \\
Carprofeno & 2,2 & Oral & a cada 12 horas \\
Meloxican & $0,1-0,2$ & Oral & a cada 24 horas \\
Prednisona & $0,5-1$ & Oral & a cada 24 horas \\
Tramadol & 2 & Oral & a cada 8 horas \\
\hline
\end{tabular}

Quadro 1- Fármacos (dose, via e freqüência) utilizados para o alívio da dor

Os antiinflamatórios não foram utilizados em cães que apresentassem contraindicações ao seu uso, tais como vômito, diarréia, insuficiência renal, doenças hepáticas, trombocitopenia e insuficiência cardíaca. Nos cães com neoplasia renal, hepática ou esplênica e cães com qualquer contra-indicação ao uso destes, optou-se pelo uso de dipirona e tramadol. 


\subsubsection{Fármacos adjuvantes empregados durante o tratamento}

A amitriptilina foi empregada nos cães com suspeita de dor neuropática, na dose de 0,5 a 1mg/Kg a cada 24 horas, pela via oral. Os critérios utilizados para a suspeita diagnóstica de dor neuropática foram a presença de pelo menos um dos seguintes sinais tais como: presença de alodinia táctil; presença de automutilação ou lambedura excessiva no local da neoplasia.

\subsubsection{Avaliação da dor e da Qualidade de Vida (QV)}

5.4.4.1 Avaliação da dor

A dor foi avaliada em relação a sua intensidade através da Escala Numérica Verbal (AMARAL et al., 1996) de zero a dez, onde zero significa ausência de dor e dez a pior dor imaginável. A avaliação foi realizada semanalmente pelo proprietário ou cuidador do animal e pelo pesquisador durante a anamnese e exame físico.

5.4.4.2 Avaliação da qualidade de vida (QV)

Avaliação da QV foi realizada semanalmente pelo proprietário através de um questionário de avaliação de QV validado para uso em cães com dor secundária ao câncer (YAZBEK; FANTONI, 2005) (Anexo A). O questionário contém 12 perguntas com 4 opções de resposta, variando de zero a 3 cada, onde zero significa a pior QV e 36 a melhor QV. Na escala são avaliados parâmetros como: apetite, dor, alterações comportamentais (temperamento e interação com as pessoas da casa), qualidade do sono, hábitos de higiene, defecação, presença de vômito e alterações intestinais, cansaço e disposição para brincadeiras. 


\subsubsection{Cuidados paliativos}

5.4.5.1 Fármacos utilizados para prevenção e tratamento dos efeitos adversos

O câncer bem como os fármacos utilizados para o tratamento da dor promovem inúmeros efeitos adversos passíveis de tratamento e que no presente estudo foram controlados com as seguintes medicações: metoclopramida $(0,5 \mathrm{mg} / \mathrm{kg}$ por via oral a cada 8 horas) para os cães com suspeita de náusea causada pelo tramadol e por via subcutânea nos cães com vômitos; ranitidina (2 a 3mg/kg por via oral a cada 12 horas) para os cães com mastocitoma, insuficiência renal e vômitos; cães que receberam antiinflamatórios foram medicados com omeprazol (0,5 a 1mg/kg por via oral a cada 24 horas) para a prevenção de gastrite e úlcera.; dimeticona (1 gota para cada kg de peso a cada 8 a 12 horas) para os cães com suspeita de flatulências e conseqüente desconforto abdominal; furosemida $(2 \mathrm{mg} / \mathrm{kg}$ por via oral a cada 8 horas) e/ou espironolactona ( 1 a $4 \mathrm{mg} / \mathrm{kg}$ por via oral a cada 8 a 12 horas) para os cães com efusão pleural, edema pulmonar e ascite secundárias a presença da neoplasia; antibióticos como a ampicilina (22mg/kg por via oral a cada 8 horas) e enrofloxacina (5mg/kg por via oral a cada 12 horas) para os cães com ulcerações tumorais e infecções secundárias; supositório de glicerina para os cães com constipação causada pelo tramadol ou por decúbito prolongado.

5.4.5.2 Manejo de ulcerações tumorais, fraturas patológicas e escaras de decúbito.

As ulcerações tumorais foram tratadas com soluções anti-sépticas a base de triclorsan (Soapex ${ }^{\circledR}$ ) e produtos cicatrizantes e bactericidas (Bactroban ${ }^{\circledR}$; Rifocina spray ${ }^{\circledR}$; Furacin ${ }^{\circledR}$ ) com curativos e bandagens realizadas pelos proprietários. Quando necessário, administrava-se os antibióticos sistêmicos para o controle das infecções secundárias.

Para os animais em decúbito, orientou-se a aquisição de colchão casca de ovo para a prevenção de escaras. A higiene e o manejo dos animais foram realizados pelos proprietários. 


\subsubsection{Manejo nutricional}

Todos os proprietários foram orientados a oferecer aos animais dieta de alta palatabilidade como, por exemplo, dieta caseira (frango, arroz, legumes etc), ração úmida e frutas.

\subsubsection{Eutanásia}

A eutanásia foi indicada somente para os animais com QV inferior a 12 ou nos casos de dor não responsiva ao tratamento medicamentoso. Todos os animais foram sedados previamente com acepromazina na dose de 0,1 mg/kg por via intramuscular. Decorridos 10 minutos, a veia cefálica foi cateterizada para a administração de tiopental em dose suficiente para promover a parada cardiorrespiratória. A necropsia não foi exigida pelo pesquisador uma vez que não fazia parte do objetivo do estudo.

\subsection{COLETA DE DADOS DURANTE O ESTUDO}

\subsubsection{Informações coletadas}

- Número de identificação do animal no Hospital Veterinário (prontuário).

- Sexo, idade e raça.

- Principais alterações e sintomas relatados pelo proprietário durante a anamnese na primeira consulta, antes do início da terapia com tramadol.

- Localização primária da neoplasia e presença de metástase visível aos exames complementares.

- $\quad$ Escore de QV. 
- Em relação à dor foram realizadas as seguintes perguntas:

- O seu animal sente dor?

(Possibilidades de resposta: Sim, não ou não sei).

- Nota para a dor de zero (ausência de dor) a dez (pior dor imaginável) de acordo com a Escala Numérica Verbal.

- Desde que está com dor, o seu animal apresentou aumento, diminuição ou não apresentou alteração em relação a: ansiedade, alegria, tristeza, carência, medo, docilidade, agressividade, vocalização, mobilidade, higiene, brincadeiras, curiosidade, sono, apetite, sociabilidade e interesse? (WISEMAN et al., 2001)

\subsubsection{Informações coletadas em relação ao emprego do tramadol}

- Doses e freqüência mínima e máxima do tramadol.

- Prescrição de fármacos adjuvantes e realização de cuidados paliativos.

- Principais efeitos adversos causados pelo tramadol.

- Tempo total de tratamento em dias.

- Avaliação da dor através da ENV (proprietário e pesquisador).

- $\quad$ Escore de QV.

\subsection{MOMENTOS DE AVALIAÇÃO PARA ANÁLISE DA TERAPÊUTICA}

Para a coleta dos dados dos animais incluídos na avaliação da eficácia terapêutica analgésica e paliativa, optou-se por analisar 3 momentos: primeira consulta, primeiro retorno (7 dias), segundo retorno (14dias). 


\subsection{ANÁLISE ESTATÍSTICA}

As variáveis obtidas foram confrontadas estatisticamente através de provas paramétricas, utilizando-se para tal a análise de variância ANOVA seguida do teste de TukeyKramer,bem como dos testes de Freidman e Wilcoxon através de programa de computador (SPSS) para comparação dos valores obtidos nos diferentes tempos de observação. Foi estabelecido o grau de significância de $5 \%(\mathrm{p}<0,05)$.

As variáveis não paramétricas foram analisadas através do Teste de Mann-Whitney-U. 


\section{RESULTADOS}

Foram encaminhados para o estudo 130 cães com câncer, 53 machos (40,77\%) e 77 fêmeas (59,23\%), no período de agosto de 2004 a março de 2006 (Apêndices B a D, Quadros 2 a 4). Cães com idade entre 10 a 14 anos foram os de maior freqüência, seguidos de animais de 5 a 9 anos (Tabela 1). As raças mais freqüentes foram os cães sem raça definida, seguida de Rottweiller, Pastor Alemão, Poodle e Boxer (Tabela 2).

Tabela 1 - Idade dos 130 cães atendidos durante o estudo

\begin{tabular}{ccc}
\hline Idade & Número de cães & $\mathbf{\%}$ \\
\hline$<5$ anos & 8 & 6,15 \\
5 a 9 anos & 28 & 21,54 \\
10 a 14 anos & 82 & 63,08 \\
$>$ 14 anos & 07 & 5,38 \\
Desconhecida & 05 & 3,85 \\
Total & $\mathbf{1 3 0}$ & $\mathbf{1 0 0}$ \\
\hline
\end{tabular}

Tabela 2 - Distribuição racial dos 130 cães atendidos durante o estudo

\begin{tabular}{ccc}
\hline Raça & Número de cães & $\mathbf{\%}$ \\
\hline Sem raça definida & 34 & 26,15 \\
Rottweiller & 15 & 11,54 \\
Pastor Alemão & 14 & 10,77 \\
Poodle & 13 & 10,00 \\
Boxer & 7 & 5,38 \\
Cocker Spaniel & 4 & 3,08 \\
Fila Brasileiro & 4 & 3,08 \\
Fox Paulistinha & 4 & 3,08 \\
Husky Siberiano & 4 & 3,08 \\
Bassethound & 3 & 2,30 \\
Labrador & 3 & 2,30 \\
Akita & 2 & 1,54 \\
Dachshund & 2 & 1,54 \\
Dobermann & 2 & 1,54 \\
Dog Alemão & 2 & 1,54 \\
Pastor Belga & 2 & 1,54 \\
Pinscher & 2 & 1,54 \\
Setter Irlandês & 2 & 1,54 \\
Outras & 11 & 8,46 \\
Total & $\mathbf{1 3 0}$ & $\mathbf{1 0 0}$ \\
\hline
\end{tabular}


Em relação à presença de metástases, 54 cães (41,54\%) apresentavam metástase visível aos exames complementares como radiografia e ultra-sonografia e 76 cães (58,46\%) não apresentavam sinais de metástase na consulta. Em relação ao local primário do tumor, os ossos, tecidos moles e glândula mamária foram os locais de maior incidência (Tabela 3) (Apêndices E a G, Quadros 5 a 7).

Tabela 3 - Localização do tumor primário dos 130 cães atendidos durante o estudo

\begin{tabular}{ccc}
\hline Localização do tumor primário & Número de cães & $\mathbf{\%}$ \\
\hline Osso & 45 & 34,61 \\
Tecidos moles & 29 & 22,31 \\
Glândula Mamária & 19 & 14,62 \\
Fígado & 11 & 8,46 \\
Baço & 7 & 5,38 \\
Boca e nariz & 6 & 4,61 \\
Pulmão & 5 & 3,85 \\
Linfático & 3 & 2,31 \\
Testículo e bolsa escrotal & 2 & 1,54 \\
Intestino & 1 & 0,77 \\
Mediastino & 1 & 0,77 \\
Vesícula urinária & 1 & 0,77 \\
Total & $\mathbf{1 3 0}$ & $\mathbf{1 0 0}$ \\
\hline
\end{tabular}

As principais alterações e sintomas relatados pelos proprietários no momento de instituição da terapêutica com o tramadol foram dor, disorexia, aumento de volume, claudicação e dificuldade respiratória, dentre outras demonstradas na tabela 4 (Apêndices $\mathrm{H}$ a K, Quadros 8 a 11). Além das alterações citadas, outras 44 foram relatadas com freqüência igual ou inferior a 4. Três proprietários não relataram quaisquer sinais ou alterações ocorridas e 1 não soube relatar. O período médio de tempo em dias transcorridos depois do início das alterações até a data da primeira avaliação do paciente pelo pesquisador foi de 85,96 \pm 92,82. 
Tabela 4 - Principais sinais e alterações relatados pelos proprietários dos 130 cães atendidos durante o estudo

\begin{tabular}{ccc}
\hline Principais Sinais e Alterações & Número de proprietário & $\mathbf{\%}$ \\
\hline Dor & 46 & 35,38 \\
Disorexia & 35 & 26,92 \\
Aumento de volume & 34 & 26,15 \\
Claudicação & 25 & 19,23 \\
Dificuldade respiratória & 12 & 9,23 \\
Tosse & 10 & 7,7 \\
Dificuldade locomotora & 8 & 6,15 \\
Emagrecimento & 8 & 6,15 \\
Cansaço fácil & 7 & 5,38 \\
Prostração & 7 & 5,38 \\
Emese & 7 & 5,38 \\
\hline
\end{tabular}

Em relação à avaliação da dor, somente 7 proprietários (5,38 \%) apresentaram dificuldade em avaliar a dor através da ENV. Nenhum proprietário apresentou dificuldade em responder o questionário de qualidade de vida durante todo o estudo.

Dos 130 cães encaminhados para o estudo 34 (26,15\%) não retornaram, 4 (3,08\%) foram eutanasiados e $1(0,76 \%)$ morreu antes de ser iniciado o tratamento com o tramadol. Não retornaram após a consulta onde se iniciou a terapia com o tramadol 19 (14,61\%) animais, outros 7 (5,38\%) foram eutanasiados no primeiro retorno e $1(0,76 \%)$ morreu antes do primeiro retorno. As causas mais freqüentes para a realização da eutanásia foram insuficiência respiratória grave, emese não controlada, caquexia e anorexia, obstrução gastrintestinal e por opção do proprietário. Somente 37 cães obedeceram aos critérios de inclusão para análise da terapia analgésica com o emprego do tramadol, os motivos pelos quais os animais foram excluídos e a freqüência em que ocorreram estão relatados na tabela 5 (Apêndice L a N, Quadros 12 a 14). Vale ainda dizer que todos os animais, inclusive os excluídos do presente estudo, receberam tratamento para o controle da dor oncológica e cuidados paliativos. O tempo médio de tratamento foi de 45,35 dias $\pm 33,57$, sendo o tratamento mínimo de 15 dias e o máximo 154 dias. 
Tabela 5 - Motivos de exclusão, número de animais excluídos e porcentagem do total de animais avaliados (130) e porcentagem do total dos animais excluídos (93).

\begin{tabular}{cccc}
\hline Motivos de exclusão & Número & Porcetagem do total & $\begin{array}{c}\text { Porcetagem dos } \\
\text { excluídos }\end{array}$ \\
\hline Não retornaram após avaliação prévia & 34 & 26,15 & 36,56 \\
Não retornaram após consulta & 19 & 14,51 & 20,43 \\
ENV < 4 & 8 & 6,15 & 8,60 \\
Eutanásia no primeiro retorno & 7 & 5,38 & 7,53 \\
Proprietário não medicou corretamente & 7 & 5,38 & 7,53 \\
Animal medicado com outro opióide & 6 & 4,62 & 6,45 \\
Eutanásia após avaliação prévia & 4 & 3,08 & 4,30 \\
Proprietário não soube quantificar a dor & 4 & 3,08 & 4,30 \\
através da ENV & & & \\
Animal irascível & 1 & 0,76 & 1,08 \\
Dor crônica não oncológica & 1 & 0,76 & 1,08 \\
Não medicou com dipirona & 1 & 0,76 & 1,08 \\
Òbito após avaliação prévia & 1 & 0,76 & 1,08 \\
Óbito após consulta & 1 & 0,76 & 1,08 \\
\hline
\end{tabular}

As principais alterações comportamentais percebidas desde o início dos sintomas e relatadas pelos proprietários dos 37 animais que perfazem os grupos de estudo foram o aumento da carência e redução da mobilidade, alegria, disposição para brincadeiras, apetite, curiosidade e interesse, dentre outras alterações demonstradas e quantificadas na tabela 6.

Tabela 6 - Principais alterações comportamentais relatas pelos proprietários dos 37 cães submetidos no momento de instituição da terapêutica com o tramadol

\begin{tabular}{ccccccc}
\hline Comportamento & \multicolumn{2}{c}{ Aumentou } & \multicolumn{2}{c}{ Não Mudou } & \multicolumn{2}{c}{ Diminuiu } \\
\cline { 2 - 7 } Sono & Número & $\mathbf{\%}$ & Número & $\mathbf{\%}$ & Número & $\%$ \\
Apetite & 16 & 43,24 & 11 & 29,73 & 10 & 27,03 \\
Ansiedade & 1 & 2,70 & 14 & 37,84 & 22 & 59,46 \\
Alegria & 2 & 5,41 & 24 & 64,86 & 11 & 29,73 \\
Carência & 0 & 0 & 9 & 24,32 & 28 & 75,68 \\
Medo & 18 & 48,65 & 13 & 35,14 & 6 & 16,21 \\
Agressividade & 5 & 13,51 & 31 & 83,79 & 1 & 2,7 \\
Vocalização & 7 & 18,92 & 29 & 78,38 & 1 & 2,70 \\
Mobilidade & 13 & 35,14 & 19 & 51,35 & 5 & 13,51 \\
Higiene & 0 & 0 & 7 & 18,92 & 30 & 81,08 \\
Brincadeiras & 3 & 8,11 & 24 & 64,86 & 10 & 27,03 \\
Curiosidade & 0 & 0 & 7 & 18,92 & 30 & 81,08 \\
Sociabilidade & 0 & 0 & 22 & 59,46 & 15 & 40,54 \\
Interesse & 1 & 2,70 & 23 & 61,16 & 13 & 35,14 \\
\end{tabular}


De acordo com a avaliação dos proprietários, a média de dor dos animais avaliados através da ENV no momento de instituição da terapêutica com o tramadol foi de 6,11 \pm 1,81 e o escore de qualidade de vida foi 21,95 \pm 5,96. Já a média de dor dos animais através da ENV neste mesmo momento de acordo com o pesquisador foi de 5,24 $\pm 1,44$.

A avaliação da dor realizada, nos diferentes momentos durante o tratamento, pelo proprietário e pesquisador através da ENV, está demonstrada na tabela 7. Observou-se correlação positiva entre as duas avaliações em todos os momentos (Figuras 1, 2 e 3). Comparando-se as duas avaliações não se observou diferença estatística (Figura 4). Na opinião do proprietário, observou-se significativa redução da dor em todos os momentos em relação ao momento de instituição da terapêutica com o tramadol (Tabela 7). De acordo com a avaliação do pesquisador, houve redução da dor em todos os momentos comparando-se a avaliação inicial (Tabela 7). A avaliação individual da dor, nos 3 diferentes momentos em cada grupo , está demonstrada nos quadros 15 a 17 (Apêndice Q a R).

Tabela 7 - Avaliação da dor realizada pelo proprietário e pesquisador através da Escala Numérica Verbal (ENV) dos 37 cães incluídos para avaliação da terapia analgésica com tramadol nos diferentes momentos de avaliação

\begin{tabular}{cccc}
\hline Momentos & ENV Pesquisador & ENV Proprietário & Grau de Significância \\
\hline Consulta & $5,24 \pm 1,44^{\mathrm{Aa}}$ & $6,10 \pm 1,80^{\mathrm{Ab}}$ & $p<0,016$ \\
Primeiro Retorno & $3,51 \pm 1,40^{\mathrm{Ba}}$ & $3,43 \pm 2,13^{\mathrm{Ba}}$ & $p>0,76$ \\
Segundo Retorno & $2,86 \pm 1,66^{\mathrm{Ca}}$ & $2,56 \pm 1,80^{\mathrm{Ca}}$ & $p>0,110$ \\
Grau de significância & $p<0,02$ & $p<0,014$ & \\
\hline
\end{tabular}

Letras minúsculas distintas na mesma linha indicam diferenças estatísticas entre si.

Letras maiúsculas distintas na mesma coluna indicam diferenças estatísticas entre si. 


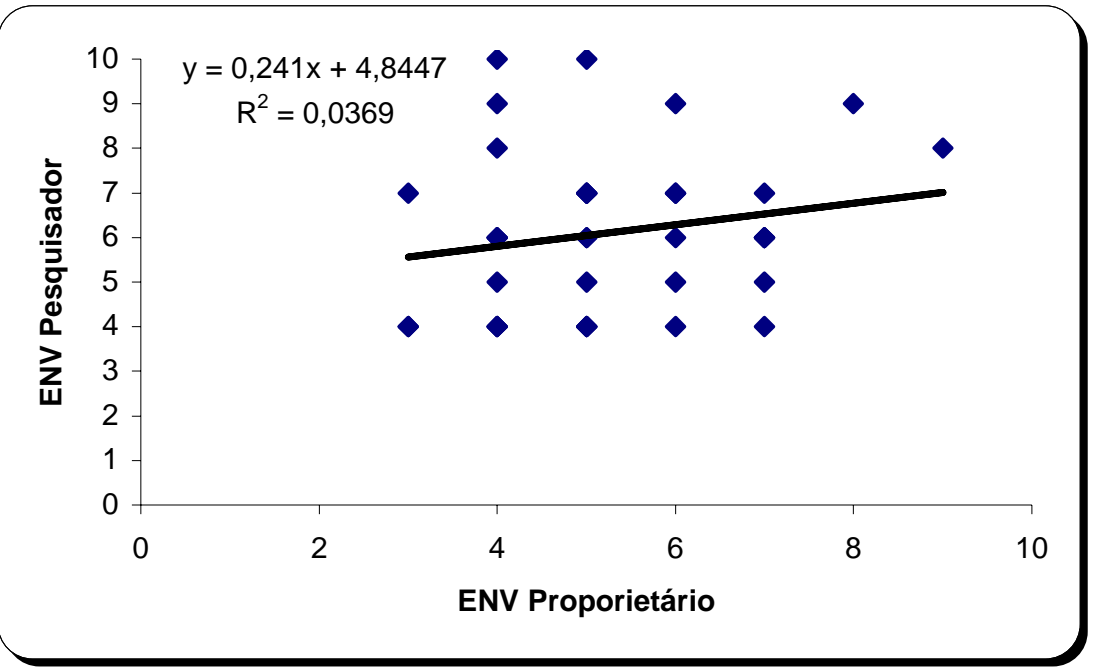

Figura 1 - Correlação entre a avaliação de dor realizada pelo proprietário e pesquisador através da Escala Numérica Verbal (ENV) na consulta

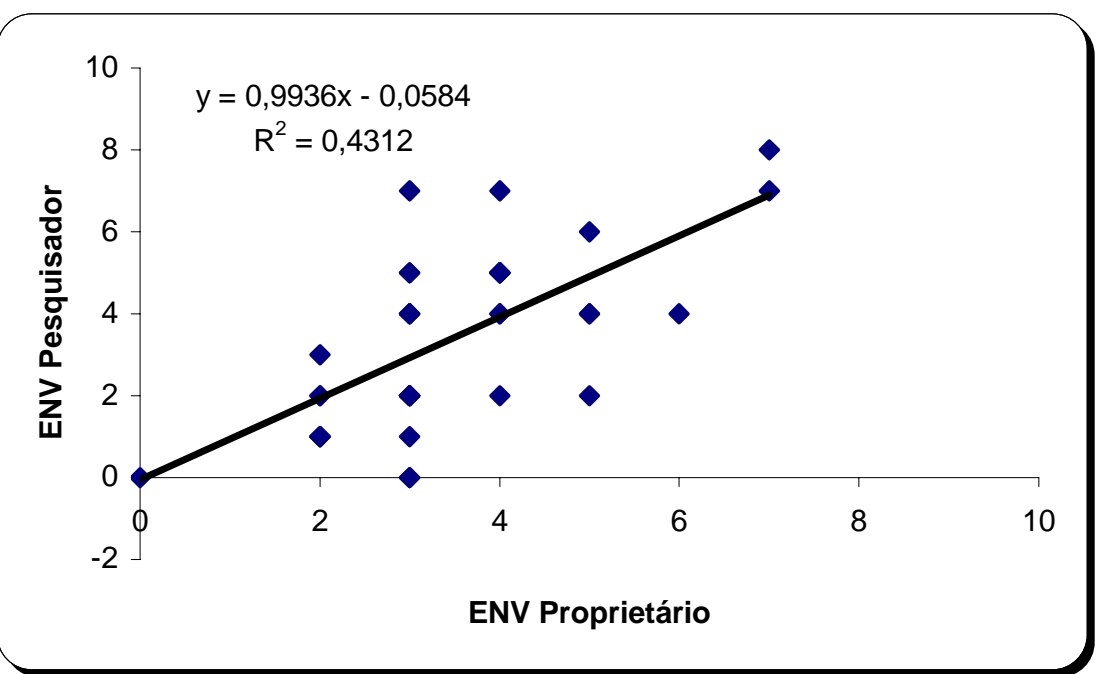

Figura 2 - Correlação entre a avaliação de dor realizada pelo proprietário e pesquisador através da Escala Numérica Verbal (ENV) no primeiro retorno 


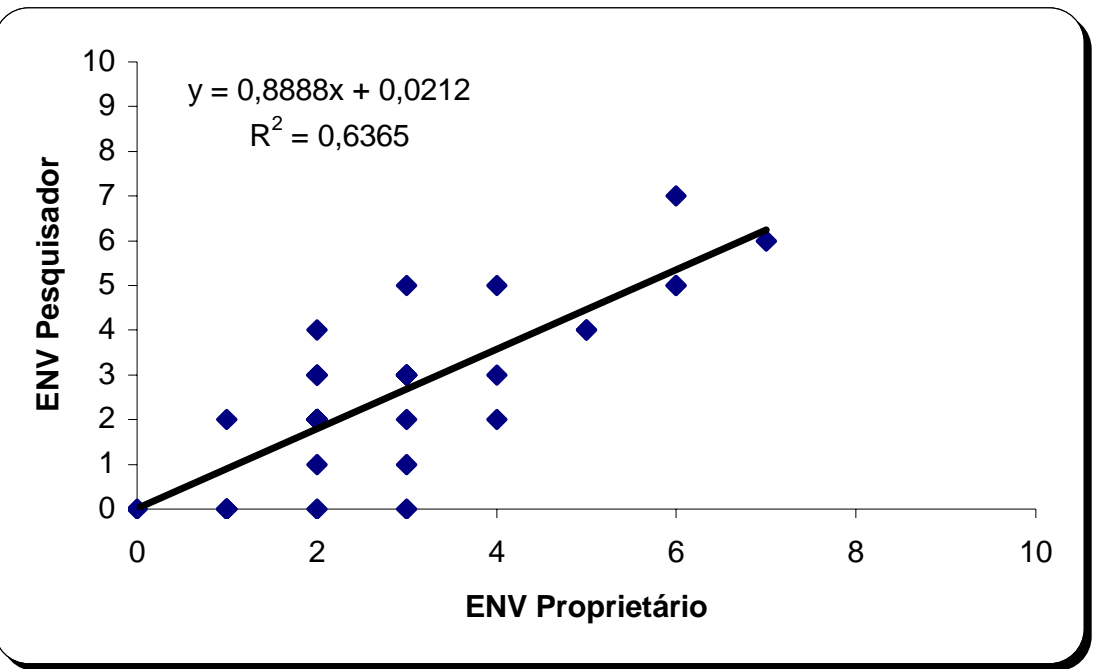

Figura 3 - Correlação entre a avaliação de dor realizada pelo proprietário e pesquisador através da Escala Numérica Verbal (ENV) no segundo retorno

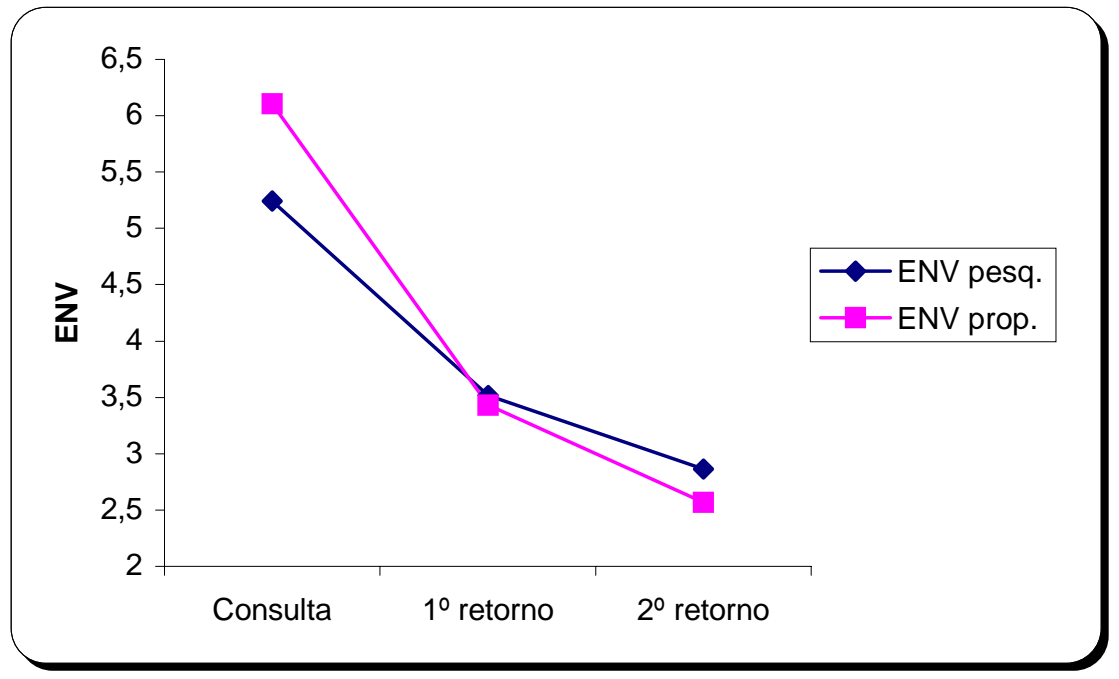

Figura 4 - Avaliação da dor dos 37 animais realizada através da Escala Numérica Verbal (ENV) nos 3 diferentes momentos de avaliação durante o experimento 
Na opinião do pesquisador a intensidade da dor, no momento de instituição da terapêutica com o tramadol, foi considerada leve em 3 (8,01\%) dos pacientes, moderada em 26 (70,27\%) e intensa em 8 (21,62\%); porém na avaliação do proprietário, determinante para o início do tratamento, a dor foi considerada moderada em 23 (62,16\%) e intensa em 14 (37,83\%) dos 37 animais incluídos no estudo, os animais com intensidade da dor considerada leve pelo proprietário foram excluídos do estudo.

No primeiro retorno verificou-se melhora da dor em 29 (78,38\%) dos pacientes, na opinião do pesquisador, e em 31 (83,78\%) na opinião do proprietário. Neste momento foi realizada correção da dose do tramadol, considerando-se a intensidade da dor relatada pelo proprietário, em 20 (54,05\%) dos 37 cães (ENV superior a 4).

No segundo retorno 31 (83,78\%) dos animais, na opinião do pesquisador, e 34 (91,89\%), na do proprietário apresentaram alívio da dor em relação à consulta inicial, sendo que 28 (75,68\%) destes obtiveram ENV inferior a 4 na opinião de ambos avaliadores.

O escore de qualidade de vida obtido pelos cães no primeiro e segundo retornos foi considerado estatisticamente superior ao início do tratamento $(\mathrm{p}<0,0001)$ vale ainda dizer que houve aumento do escore de qualidade de vida no segundo retorno em relação ao primeiro com grau de significância $\mathrm{p}<0,045$ conforme dados da tabela 8 e figura 5 . A avaliação individual da qualidade de vida, nos 3 diferentes momentos em cada grupo, está demonstrada nos quadros 15 a 17 (Apêndice Q a R).

Tabela 8 - Médias do escore de qualidade de vida dos 37 cães incluídos para avaliação da terapia analgésica com tramadol nos diferentes momentos de avaliação

\begin{tabular}{cccc}
\hline Momentos & Consulta & Primeiro Retorno & Segundo Retorno \\
\hline Qualidade de Vida & $21,95 \pm 5,96$ & $25,49 \pm 4,89$ & $26,59 \pm 4,83$ \\
\hline
\end{tabular}




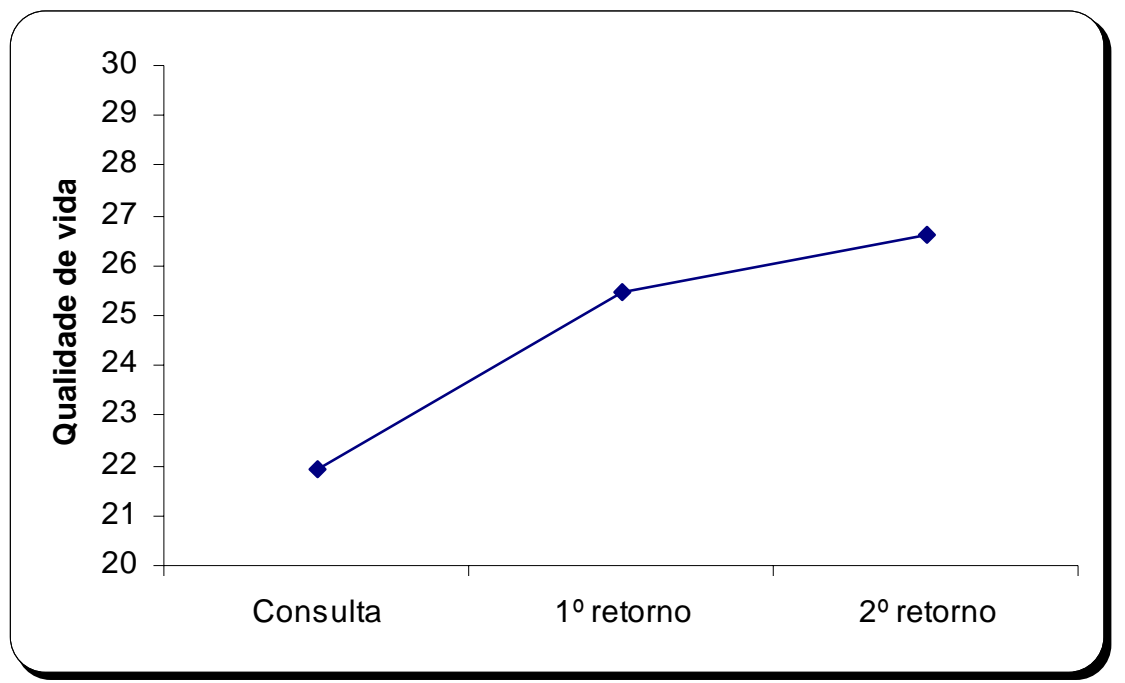

Figura 5 - Média dos escores de qualidade de vida dos 37 cães nos diferentes momentos de avaliação durante o tratamento

Em relação aos fármacos utilizados para o controle de efeitos adversos e cuidados paliativos, utilizou-se com maior freqüência o omeprazol, os antibióticos, a ranitidina, a metoclopramida, os anti-sépticos e a dimeticona (Tabela 9). Cirurgia paliativa foi realizada em 3 cães, sendo 2 amputações e 1 pneumectomia, abdominocentese para drenagem de líquido ascítico foi realizada em 2 cães e curativos diários foram necessários em 5 cães.

Tabela 9 - Fármacos empregados para controle de efeitos adversos e sintomas dos 37 cães incluídos no estudo

\begin{tabular}{ccc}
\hline Fármacos & Total de cães & $\%$ \\
\hline Omeprazol & 14 & 37,83 \\
Antibióticos & 9 & 24,32 \\
Ranitidina & 7 & 18,92 \\
Anti-sépticos & 5 & 13,51 \\
Dimeticona & 4 & 10,81 \\
Escopolamina & 3 & 8,11 \\
Espironolactona & 3 & 8,11 \\
Supositório de glicerina & 3 & 8,11 \\
Furosemida & 2 & 5,41 \\
Metoclopramida & 2 & 5,41 \\
Óleo mineral & 2 & 5,41 \\
Anti-séptico e spray bucal & 1 & 2,70 \\
\hline
\end{tabular}


A amitriptilina foi empregada em 9 cães com suspeita de dor neuropática, na dose de 0,5 a $1 \mathrm{mg} / \mathrm{Kg}$ a cada 24 horas, pela via oral.

A distribuição dos 37 animais em 3 grupos diferentes foi realizada conforme a indicação ou não de prescrição de antiinflamatórios não esteroidais ou esteroidais. A tabale 10 relaciona a conformação dos grupos.

Tabela 10 - Associações de fármacos associada a cada grupo e número total de animais em cada

\begin{tabular}{ccc}
\hline Grupos & Associações de fármacos & Número de animais \\
\hline Grupo DT & Dipirona + tramadol & 8 \\
Grupo DAINET & Dipirona + antiinflamatório não esteroidal + tramadol & 23 \\
Grupo DET & Dipirona + antiinflamatório esteroidal + tramadol & 6 \\
Total & & 37 \\
\hline
\end{tabular}

A média e o desvio padrão do escore de dor e do escore de qualidade de vida dos grupos nos diferentes momentos de avaliação, bem como sua avaliação estatística, estão demonstrados nas de tabela 11 a 13 e nas figuras de 6 a 9 .

Tabela 11 - Avaliação da dor realizada pelo proprietário e pesquisador através da Escala Numérica Verbal (ENV) e valor do escore de qualidade de vida (QV) dos cães incluídos para avaliação da terapia analgésica com tramadol no Grupo DT

\begin{tabular}{cccc}
\hline Momentos & ENV Pesquisador & ENV Proprietário & $\begin{array}{c}\text { Qualidade de } \\
\text { vida }\end{array}$ \\
\hline Consulta & $5,25 \pm 1,49^{\mathrm{a}}$ & $5,25 \pm 2,05^{\mathrm{a}}$ & $21,50 \pm 4,75^{\mathrm{a}}$ \\
Primeiro Retorno & $3,25 \pm 1,67^{\mathrm{b}}$ & $2,25 \pm 2,05^{\mathrm{b}}$ & $24,00 \pm 5,40^{\mathrm{ab}}$ \\
Segundo Retorno & $2,25 \pm 1,49^{\mathrm{b}}$ & $1,88 \pm 1,36^{\mathrm{b}}$ & $26,00 \pm 4,04^{\mathrm{b}}$ \\
Grau de & $p<0,015$ & $p<0,018$ & $p<0,012$ \\
significância & & & \\
\hline
\end{tabular}

Letras minúsculas distintas na mesma linha indicam diferenças estatísticas entre si. 
Tabela 12 - Avaliação da dor realizada pelo proprietário e pesquisador através da Escala Numérica Verbal (ENV) e valor do escore de qualidade de vida (QV) dos cães incluídos para avaliação da terapia analgésica com tramadol no Grupo DAINET

\begin{tabular}{cccc}
\hline Momentos & ENV Pesquisador & ENV Proprietário & $\begin{array}{c}\text { Qualidade de } \\
\text { vida }\end{array}$ \\
\hline Consulta & $5,04 \pm 1,36^{\mathrm{a}}$ & $6,35 \pm 1,80^{\mathrm{a}}$ & $22,35 \pm 6,83^{\mathrm{a}}$ \\
Primeiro Retorno & $3,89 \pm 1,22^{\mathrm{b}}$ & $4,17 \pm 1,92^{\mathrm{b}}$ & $25,57 \pm 4,48^{\mathrm{b}}$ \\
Segundo Retorno & $3,00 \pm 1,60^{\mathrm{c}}$ & $2,70 \pm 1,66^{\mathrm{c}}$ & $26,74 \pm 5,13^{\mathrm{c}}$ \\
Grau de & $p<0,016$ & $p<0,0001$ & $p<0,03$ \\
significância & & & \\
\hline
\end{tabular}

Letras minúsculas distintas na mesma linha indicam diferenças estatísticas entre si.

Tabela 13 - Avaliação da dor realizada pelo proprietário e pesquisador através da Escala Numérica Verbal (ENV) e valor do escore de qualidade de vida (QV) dos cães incluídos para avaliação da terapia analgésica com tramadol no Grupo DET

\begin{tabular}{cccc}
\hline Momentos & ENV Pesquisador & ENV Proprietário & $\begin{array}{c}\text { Qualidade de } \\
\text { vida }\end{array}$ \\
\hline Consulta & $6,00 \pm 1,67^{\mathrm{a}}$ & $6,33 \pm 1,36^{\mathrm{a}}$ & $21,00 \pm 4,10^{\mathrm{a}}$ \\
Primeiro Retorno & $2,50 \pm 1,38^{\mathrm{b}}$ & $2,16 \pm 1,94^{\mathrm{b}}$ & $27,17 \pm 5,99^{\mathrm{ab}}$ \\
Segundo Retorno & $3,17 \pm 1,94^{\mathrm{b}}$ & $3,00 \pm 2,75^{\mathrm{b}}$ & $26,83 \pm 5,40^{\mathrm{b}}$ \\
Grau de & $p<0,003$ & $p<0,009$ & $p<0,03$ \\
significância & & & \\
\hline
\end{tabular}

Letras minúsculas distintas na mesma linha indicam diferenças estatísticas entre si. 


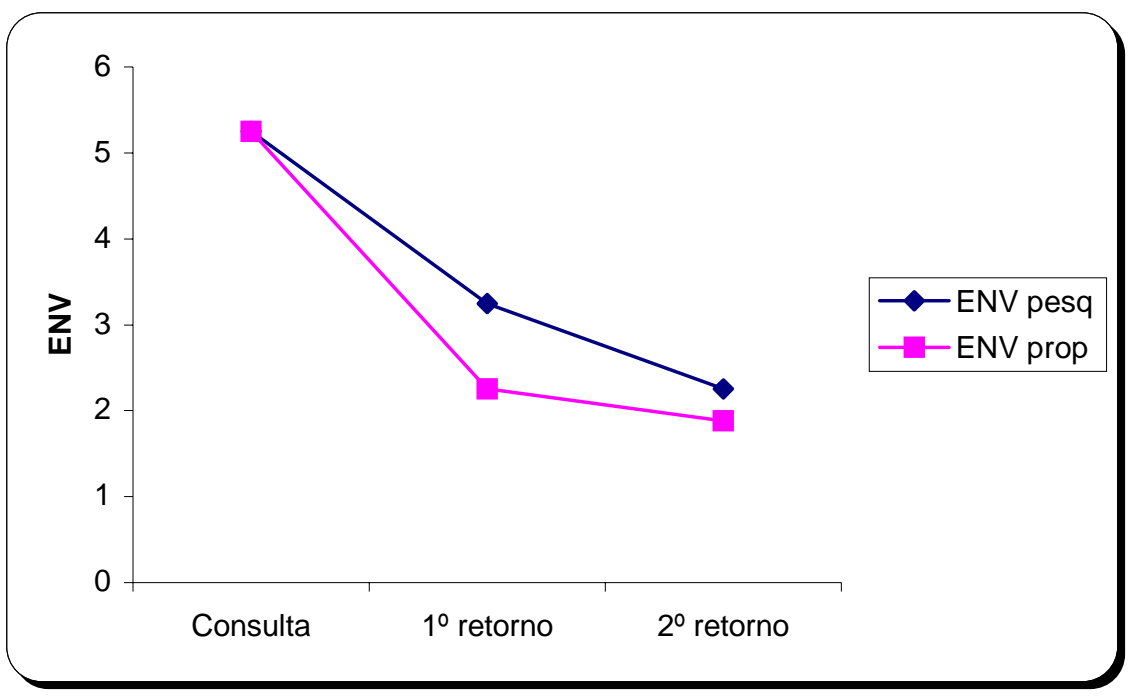

Figura 6 - Avaliação da dor dos animais do Grupo DT, realizada através da Escala Numérica Verbal (ENV) nos 3 diferentes momentos de avaliação durante o experimento

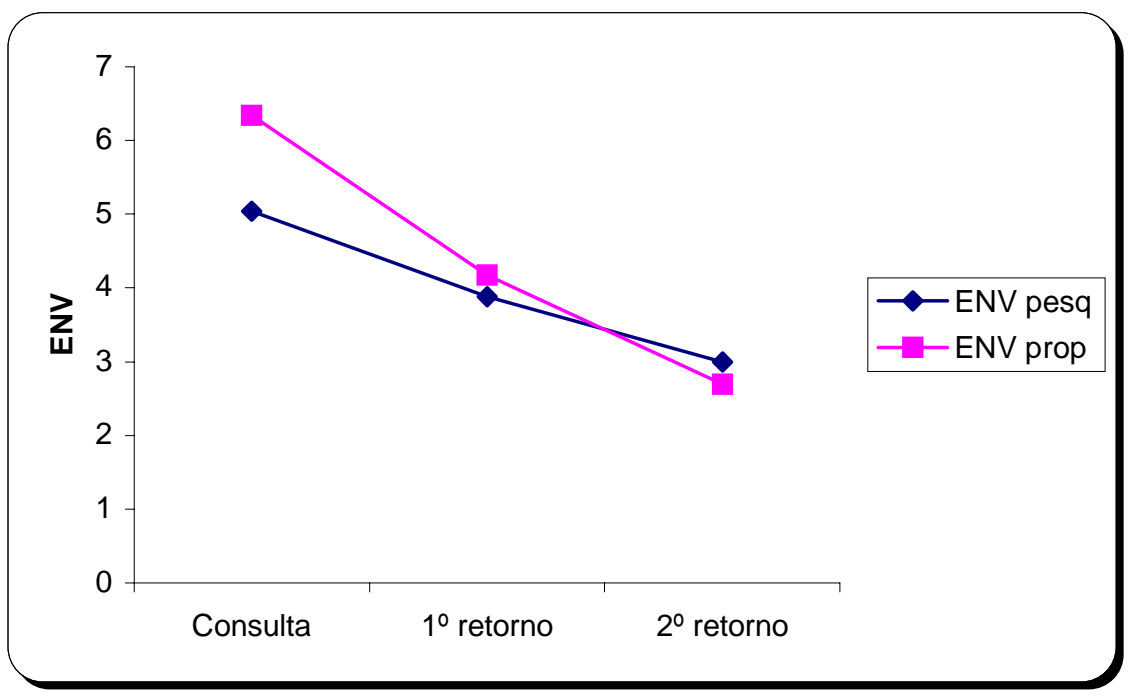

Figura 7 - Avaliação da dor dos animais do Grupo DAINET, realizada através da Escala Numérica Verbal (ENV) nos 3 diferentes momentos de avaliação durante o experimento 


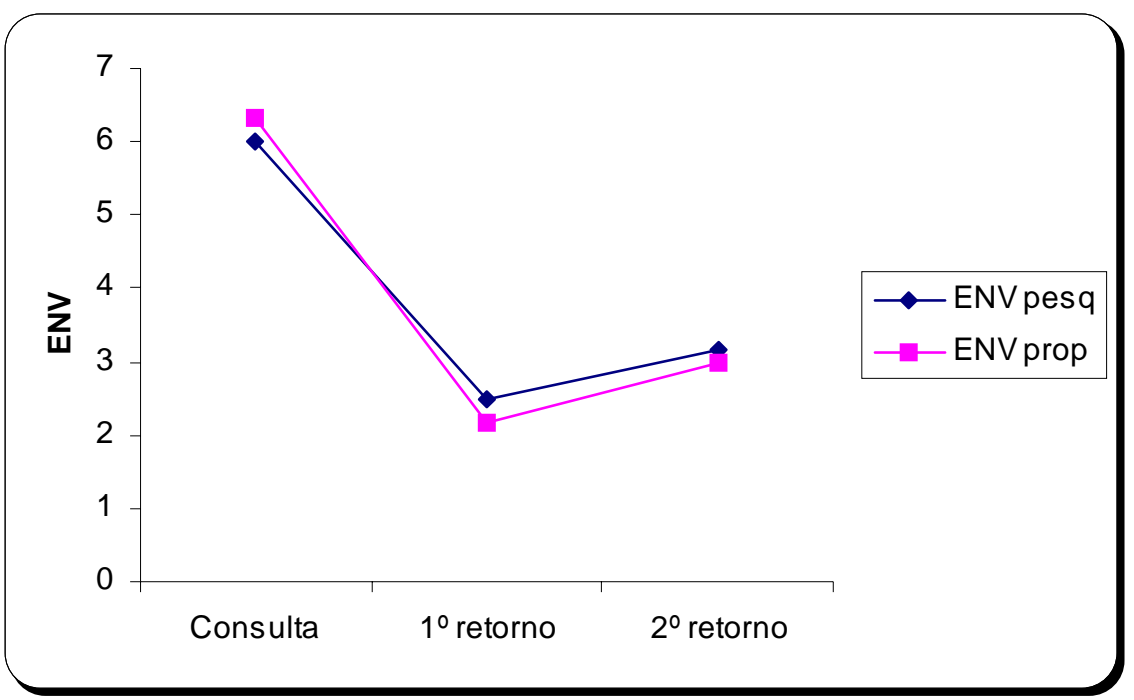

Figura 8 - Avaliação da dor dos animais do Grupo DET, realizada através da Escala Numérica Verbal (ENV) nos 3 diferentes momentos de avaliação durante o experimento

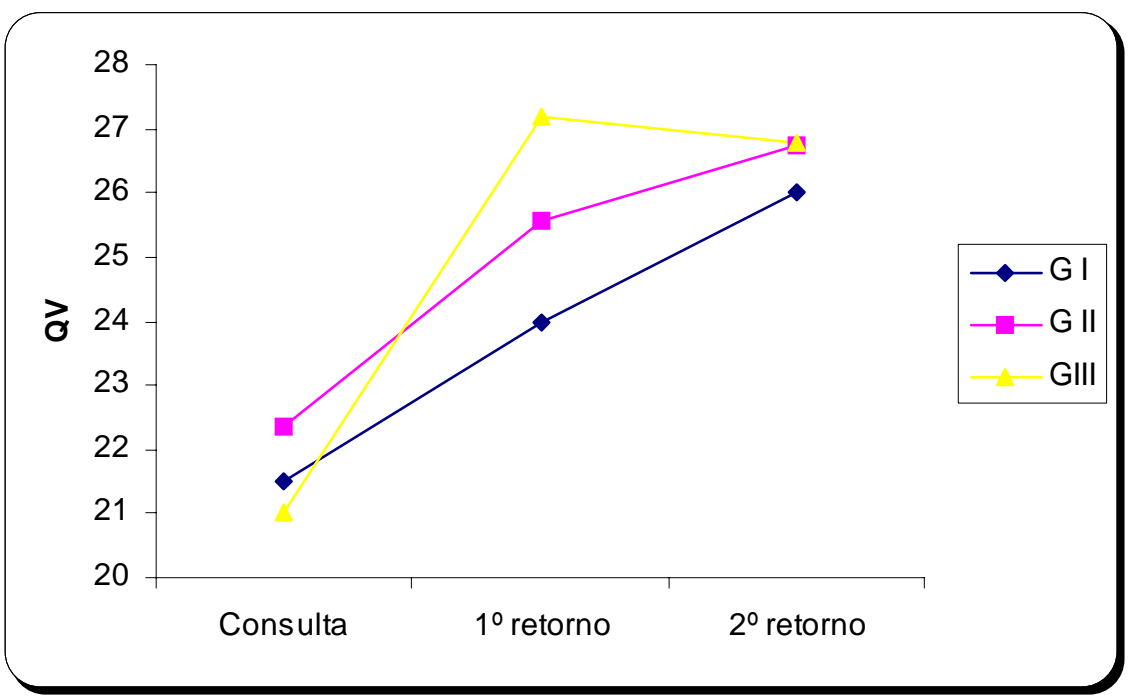

Figura 9 - Escore de qualidade de vida dos grupos nos 3 diferentes momentos de avaliação durante o experimento 
O tramadol foi prescrito para todos os 37 animais que participaram do estudo, destes $11(29,73 \%)$ apresentaram efeitos adversos relacionados ao uso do tramadol, sendo que em apenas um animal foi necessária a interrupção do tratamento. Os efeitos adversos observados foram sonolência em 6 (16,22\%) cães, constipação e emese em 2 (5,41\%) cães e excitação em um $(2,71 \%)$ cão. Distribuindo os animais que apresentaram efeitos adversos entre os grupos estabelecidos no delineamento deste estudo observa-se que 1 animal no Grupo DT, 8 no Grupo DAINET e 2 no Grupo DET.

A dose inicial preconizada do tramadol foi de $2 \mathrm{mg} / \mathrm{Kg}$ a cada 8 horas, por via oral, sendo esta dose foi reajustada no retorno caso o valor de ENV relata pelo proprietário fosse maior que 4. Durante o segundo retorno o acerto da dose foi analisada para cada animal que apresentou ENV>4, as doses obtidas variaram de 2,3 a 3mg/Kg a cada 8 horas, pela via oral. Para realização da análise no estudo foi utilizada apenas os primeiros 15 dias de tratamento devido ao número de animais que permaneceram em tratamento após esse momento, no entanto todos os animais continuaram o tratamento dentro dos parâmetros estipulados para este estudo. A dose máxima do tramadol alcançada ao longo do tratamento foi de 4,5mg/Kg a cada 6 horas, por via oral. 


\section{DISCUSSÃO}

O objetivo principal da assistência realizada é o conforto dos animais e a melhora da qualidade de vida, portanto o controle eficaz da dor é de extrema importância para se obter os resultados almejados, podendo também evitar a morte ou eutanásia precoce

O aumento da expectativa de vida dos animais de estimação e o conseqüente aumento da incidência de doenças crônicas relacionadas à idade avançada, deve-se à evolução da prevenção, diagnóstico e tratamento de doenças na clínica de pequenos animais (LESTER; GAYNOR, 2000; WITHROW, 2001). O câncer tem sido apontado por vários autores, como a maior causa de morbidade e mortalidade em animais idosos de companhia (BRONSON, 1982; PROSCHOWSKY et al., 2003; WITHROW, 2001). A maioria dos cães (72,31\%) encaminhados ao estudo tinha idade superior a 10 anos, o que vem a confirmar as informações da literatura e o resultado do estudo realizado por Bronson (1982), onde se observou um aumento da incidência de óbito por neoplasias em animais com idade superior a 10 anos.

Em relação à localização primária da neoplasia, ossos $(34,61 \%)$ e tecidos moles (22,31\%) foram os locais de maior ocorrência no estudo, seguidos de glândula mamária, fígado e baço. No estudo realizado por Dobson et al. (2002) os tumores de pele e de tecidos moles são os de maior incidência no Reino Unido. Não existem estudos correlacionando a intensidade da dor, local e tipo de neoplasia em cães, somente alguns estudos epidemiológicos. Sabe-se que a dor somática, causada pela invasão do tumor em ossos, músculos e pele é de difícil controle e de grau intenso (ANDRADE FILHO, 2002; PORTENOY; LESAGE, 1999), podendo ser o motivo da elevada ocorrência de cães com neoplasias ósseas no presente estudo.

A dor é considerada o principal sintoma relatado por pacientes humanos com câncer avançado (SKAER; PHARM, 1993). A importância do alívio da dor em animais foi aceita somente nas últimas décadas do século passado onde, consensos em relação ao seu tratamento e prevenção, foram publicados na literatura médica veterinária (ACVA, 1998; HELLEBREKERS, 2002). No presente estudo, todos os proprietários foram interrogados em relação as principais alterações e sinais apresentados pelo cão desde o início da doença, e a dor foi apontada como o principal sinal em 35,38\% dos cães, seguido de disorexia (26,92\%), aumento de volume (26,15\%) e claudicação (19,23\%). Esse percentual pode ser considerado 
ainda maior se a disorexia e a claudicação forem consideradas como manifestação de dor por muitos animais e assim, não percebida e interpretada como dor pelos proprietários. Não se pode generalizar essa informação e confrontá-la com a situação de pacientes humanos, já que não foram avaliados todos os cães com câncer atendidos no hospital durante o estudo e somente os animais encaminhados para o Grupo de Dor.

Segundo Wiseman et al. (2004) a dor pode causar alterações comportamentais importantes em cães com dor crônica secundária a doença articular degenerativa como redução da mobilidade, atividade, apetite, curiosidade, sociabilidade e disposição para brincadeiras e aumento da dependência, agressividade, ansiedade, comportamentos compulsivos, medo, vocalização e mobilidade. No presente estudo, observou-se as alterações comportamentais de 37 cães com dor secundária a neoplasias de intensidade moderada a intensa. Dentre as principais alterações observou-se aumento da carência em 48,65\% dos cães e do período de sono (43,24\%) e redução da mobilidade (81,08\%), disposição para brincadeiras (81,08\%), alegria (75,68\%), apetite (59,46\%) e interesse $(48,65 \%)$. A maioria dos proprietários não relataram alterações em relação à ansiedade, medo, agressividade, vocalização, higiene e sociabilidade, como demonstrado por Wiseman et al. (2004). As alterações comportamentais também podem variar de acordo com a intensidade da dor, mas no presente estudo a maioria dos cães apresentava-se com dor moderada $(6,10 \pm 1,88)$ no momento da avaliação comportamental (primeira consulta).

O reconhecimento da dor em animais é difícil e muitas vezes frustrante (GAYNOR, 2001), por ser extremamente subjetivo e baseado em parâmetros fisiológicos e comportamentais (LESTER; GAYNOR, 2000). As alterações comportamentais podem ser graduais e somente perceptíveis por pessoas familiarizadas com o comportamento normal do animal, portanto de acordo com Wiseman et al. (2001) a pessoa mais indicada e apta a avaliar dor crônica é o proprietário ou o cuidador do animal. Até o momento não existem escalas de avaliação de dor crônica em cães, somente a indicação de uso da Escala Numérica Verbal (ENV) de zero a dez pelo cuidador e pelo pesquisador (AMARAL et al., 1996; LESTER; GAYNOR, 2001). Somente 5,38\% dos proprietários não souberam avaliar a dor através da ENV na primeira consulta. Isto demonstra a simplicidade de compreensão da escala numérica verbal e a viabilidade do seu uso durante a avaliação do tratamento da dor crônica em cães. No presente estudo, os cães foram avaliados pelo mesmo pesquisador e cuidador ou proprietário durante todo o tratamento e para análise dos resultados consideraram-se as avaliações da primeira consulta, do primeiro retorno e do segundo retorno. Observou-se uma 
correlação positiva entre as notas aferidas pelo pesquisador e proprietário em todos os momentos.

Outro parâmetro e instrumento para a avaliação da eficácia do tratamento do câncer e da dor oncológica, é a quantificação da qualidade de vida através de escalas (KAASA et al., 1988; OSOBA, 1992; SPRANGERS, 2002). Atualmente acredita-se que a dor é de grande importância clínica resultando em sofrimento e redução da qualidade de vida do animal , sendo de extrema importância aliviá-la e tratá-la (MCMILLAN, 2003; ROBERTSON, 2002) Desde então, muitos esforços estão sendo realizados para o desenvolvimento de escalas de avaliação de qualidade de vida em cães. Durante a realização deste estudo, utilizou-se uma escala para avaliação da qualidade de vida em animais com sinais de dor secundária ao câncer validada para a espécie canina (YAZBEK; FANTONI, 2005). Nenhum proprietário apresentou dificuldade em respondê-la, apresentando-se como um instrumento útil e de fácil aplicação na rotina clínica. A utilização da escala de qualidade de vida em associação com a escala numérica verbal permitiu reduzir a subjetividade da avaliação da dor dos cães incluídos no estudo.

O principal motivo de exclusão dos animais foi a desistência e a impossibilidade em retornar relatada por muitos proprietários para acompanhamento periódico. Sendo assim, para avaliação do tratamento, somente foram incluídos 37 cães dos 130 cães atendidos durante o estudo. Vale ressaltar que nenhum animal encaminhado para o estudo ficou sem tratamento e este foi realizado de acordo com as possibilidades do proprietário e do animal.

Classificando a eficácia do tratamento realizado com o tramadol em três categorias: alívio da dor (ENVinicial > ENVfinal e ENVfinal < 4), melhora insatisfatória (ENVinicial > ENVfinal e ENVfinal > 4) e ausência de melhora (ENVinicial $\leq$ ENVfinal) (TEIXEIRA et al, 1999) pode-se afirmar que ocorreu alívio inicial no primeiro retorno em 17 (45,95\%) dos animais, melhora insatisfatória em 14 (37,83\%) e não houve melhora em 6 (16,21\%) na opinião do proprietário. Analisando a opinião do pesquisador verificou-se que ocorreu alivio em 20 (75,68\%), melhora insatisfatória em 9 (24,32\%) e não houve melhora em 8 (31,62\%) dos cães. Desta maneira, no primeiro retorno 83,78\% e 78,28\% dos pacientes, na opinião de proprietário e pesquisador respectivamente, experimentaram alguma melhora da dor.

Seguindo esta mesma classificação observou-se que, no segundo retorno após acerto da dose do tramadol, o alívio da dor foi obtido em 28 (75,68\%) animais na opinião de proprietário e pesquisador e melhora insatisfatória em 6 (16,21\%) e 7 (18,91\%) pacientes, de acordo com o proprietário e pesquisador respectivamente. Esses dados confirmam o reportado 
na medicina humana por Teixeira et al. (1999) que observaram melhora da dor em 82,5\% dos pacientes portadores de dor oncológica avaliados, quando medicados com tramadol. Rodrigues e Rodrigues-Pereira (1989) descreveram a obtenção de boa analgesia em 70\% dos pacientes tratados com tramadol, ressaltando que os resultados insatisfatórios ocorreram com maior freqüência nos pacientes com dor neurapática associada.

A literatura carece de informações referentes ao emprego de tramadol na dor crônica. Quando comparado com morfina de liberação lenta, o adequado alívio da dor foi obtido em 58 a 88\% dos pacientes tratados com tramadol enquanto que a morfina promoveu melhora em 67 a 100\% dos pacientes que perfizeram estes estudos (RADBRUCH et al, 1996).

Quando comparados os grupos separadamente verifica-se que o grupo DAINET apresentou diferença estatística significante em todos os parâmetros avaliados em relação aos momentos avaliados, já os grupos DT e DET apresentaram diferença estatística apenas quando comparados primeira consulta e segundo retorno. Há a possibilidade do ocorrido dever-se ao número das amostras onde o grupo DAINET comporta 23 animais e os Grupo DT e DAINET possuem 8 e 6 cães, respectivamente. Porém é necessário dizer que a diferença entre os protocolos instituídos previamente ao início da terapia com tramadol também influencie os dados obtidos. Apesar deste fato, com base no alívio da dor e no aumento da qualidade de vida, pode-se afirmar que o tramadol foi eficiente no tratamento da dor oncológica nos três grupos avaliados.

A dose inicial do tramadol foi a indicada na literatura para o tratamento da dor aguda, de $2 \mathrm{mg} / \mathrm{kg}$ a cada 8 horas (MASTROCINQUE; FANTONI, 2003; YAZBEK; FANTONI, 2005). A dose máxima do tramadol utilizada durante o estudo foi de $4,5 \mathrm{mg} / \mathrm{kg}$ com freqüência máxima de administração de 6 em 6 horas. Radbruch et al. (1996) afirmam que comparando-se pacientes com altas doses de tramadol ( $\geq 300 \mathrm{mg} / \mathrm{dia})$ e pacientes com baixas doses de morfina ( $\leq 60 \mathrm{mg} /$ dia) apresentaram alívio da dor de forma equivalente sem diferença estatística na incidência de efeitos adversos.

No primeiro retorno 20 dos 37 animais avaliados necessitaram de correção da dose do tramadol, o que elevou a dose para o intervalo de 2,3 a 3mg/Kg, verificou-se que este acerto da dose auxiliou no alívio da dor e melhora da qualidade de vida dos cães, porém não foi possível estabelecer a posologia correta do tramadol, Deve-se considerar neste aspecto que como a dor é uma experiência sensorial subjetiva, cada animal apresenta um nível de tolerância próprio o que, de certa forma, faz com que a adequação das doses seja 
individualizada. Ainda as causas de dor, nos animais estudados, também são variadas o que mais uma vez dificulta o estabelecimento de uma dose padrão para os cães, de modo geral, com câncer.

O tramadol é um agente bem tolerado (LEWIS; HAN, 1997; PEREIRA, 1989; RICO et al, 2000; RODRIGUES; TEIXEIRA et al, 1999; WILLIANS, 1997). Os efeitos adversos manifestados em 29,73\% dos animais desta casuística foram de pequena monta. Foram representados especialmente por sonolência, constirpação e emese, sendo que apenas um animal necessitou interromper o tratamento devido aos efeitos adversos apresentados, o que indica que foi possível ou aceitável a ocorrência destes efeitos adversos. Em estudos realizados no homem, Teixeira et al (1999), observaram efeitos adversos em 28,4\% de um total 1355 pacientes tratados com tramadol, Lewis e Han relatam a ocorrência em 15,3\% em 13.802 pacientes medicados com o mesmo fármaco. Outros autores ainda relatam a freqüência de 20\% de efeitos adversos em seus estudos (RODRIGUES; PEREIRA, 1989).

Em relação à QV, observou-se aumento dos escores na avaliação realizada no primeiro retorno e no segundo retorno, considerado estatisticamente significativo.

Para amenizar a incidência dos efeitos adversos e de alterações causadas pela própria neoplasia, necessitou-se principalmente de fármacos como omeprazol, antibióticos (ampicilina e enrofloxacina), metoclopramida, ranitidina e dimeticona. Na opinião do pesquisador, o emprego desses fármacos e a realização de cuidados paliativos de maneira geral, foi de extrema importância na manutenção da qualidade de vida dos animais incluídos no estudo, apesar da incidência de efeitos adversos. Este fato vem a corroborar com a importância dada aos cuidados paliativos na literatura médica (ANDRADE FILHO, 2001; PESSINI et al., 2003) e enfatizar a necessidade da sua realização para animais com doenças crônicas.

Slater et al. (1996) realizaram um estudo em gatos com câncer onde todos os proprietários basearam-se na avaliação da qualidade de vida para a decisão da eutanásia. No presente estudo, observou-se que o questionário de avaliação da qualidade de vida foi também de extrema importância para a decisão da eutanásia durante a realização do estudo, já que as questões permitiram avaliar situações que cursam com extremo desconforto para o animal. O questionário permitiu maior interação e oportunidade de debate e discussão entre o proprietário e o pesquisador. Atualmente esta situação já ocorre na oncologia humana, onde a mensuração da qualidade de vida tem sido sugerida para avaliar o alívio dos sintomas e comparar a resposta aos tratamentos (BARROS, 2001) além de monitorar o impacto da dor e 
dos seus diversos tratamentos na sobrevida e qualidade de vida dos pacientes (CELLA; TULSKY, 1990; FRANSSON et al., 2001; GANZ, et al. 1991; KAASA et al., 1988; OSOBA, 1992). Essa situação também demonstra a expectativa dos proprietários que além da redução do tumor, desejam o alívio dos sintomas e a manutenção da qualidade de vida e bem estar do animal como demonstrado por Bronden et al. (2003).

Ao término deste estudo, vislumbra-se o extenso campo de pesquisas para aprofundar a terapêutica e o acompanhamento dos animais com câncer. O emprego de opióides aliados à instituição de protocolos padronizados pode ser fundamental para melhor compreender a eficácia do tratamento proposto, e a evolução da doença, o que ensejaria novos trabalhos. Outro aspecto que deve ser mencionado é a necessidade de discussão interdisciplinar a fim de melhorar a estratégia terapêutica, sugerindo maior número de intervenções cirúrgicas mesmo que paliativas. O médico veterinário deve estar aberto a este novo conceito terapêutico, permitindo que um número cada vez maior de animais possa se beneficiar. 


\section{CONCLUSÕES}

A análise dos resultados obtidos permitiu concluir que:

1. O tramadol demonstrou-se eficaz para o controle da dor de intensidade moderada à intensa em cães portadores de dor oncológica.

2. Apesar da ocorrência de efeitos adversos o uso do tramadol no controle da dor oncológica é factível, sendo seguro o seu emprego nestes animais.

3. Não foi possível estabelecer o melhor esquema terapêutico no que diz respeito às doses e intervalos de administração, porém pode-se afirmar que a correção da dose do tramadol deve ser realizada individualmente.

4. O uso do tramadol acarreta a ocorrência de efeitos adversos, tais como: sonolência, constipação, emese e excitação. 


\section{REFERÊNCIAS}

ACVA. Position Paper. American College of Veterinary Anesthesiologists Position paper on the treatment of pain in animals. Journal of American Veterinary Medical Association, v. 213, n. 5, p. 628-630, 1998.

ALMEIDA, T. I. Avaliação do emprego de vedaprofeno em cães submetidos a procedimentos cirúrgicos ortopédicos. 2002. 97 f. Dissertação (Mestrado em Cirurgia) Faculdade de Medicina Veterinária e Zootecnia, Universidade de São Paulo, São Paulo, 2002.

AMARAL, J. L. G.; JOAQUIM, M. R. G.; RODRIGUES, G. R.; SAKATA, R. K. Analgesia. In: AMARAL, J. L. G. Sedação, analgesia e bloqueio neuromuscular em UTI. Rio de Janeiro: Atheneu, 1996. v. 2, p. 47-74. (Série Clínicas Brasileiras de Medicina Intensiva)

ANDRADE FILHO, A. C. C. Câncer e Dor. In: Dor: diagnóstico e tratamento. São Paulo: Roca, 2001. p. 255-258.

BARROS, N. Qualidade de vida - conceito e métodos de avaliação. In: ANDRADE FILHO, A. C. C. Dor diagnóstico e tratamento. São Paulo: Roca, 2001. p. 53-62.

BENITEZ DEL ROSARIO, M. A.; PEREZ SUAREZ, M. C.; FERNANDEZ DIAZ, R.; CABREJAS SANCHEZ, A. Tratamiento del dolor oncológico crônico: el uso de los opáceos. Aten Primaria, v. 29, n. 8, p. 513-516, 2002.

BRONDEN, L. B.; RUTTEMAN, G. R.; FLAGSTAD, A.; TESKE, E. Study of dog and cat owners perceptions of medical treatment for cancer. Veterinary Record, v. 152, p. 77-80, 2003

BRONSON, R. T. Variation in age and death of dogs of different sexes and breeds. American Journal of Veterinary Research, v. 43, p. 2057-2059, 1982.

BROWN, S. A. Renal effects of nonsteroidal antiinflammatory drugs. In: KIRK, R.W. Current Veterinary Therapy. Philadelphia, Saunders, 1989, p. 1158-1161. 
CAMARGO, A. C. B.; PIMENTA, C. A. M.; EUGENIO, C. L. Dor: fisiologia, aspectos psicossomais, escalas de avaliação, epidemiologia. São Paulo: Limay, 1994. 61 p.

CARROL, G. L. Analgesics and pain. Veterinary Clinics of North America. Small Animals Practise, v. 29, n. 3, p. 701-717, 1999.

CARVALHO, W. A.; LEMONICA, L. Mecanismos celulares e moleculares da dor inflamatória. Modulação periférica e avanços terapêuticos. Revista Brasileira de Anestesiologia, v. 48, n. 2, p. 137-158, 1998.

CELLA, D. F.; TULSKY, D. S. Measuring quality-of-life today: methodological aspects. Oncology, v. 4, p. 29-38, 1990.

DENEUCH, A. J.; DUFAYET, C.; GOBY, L.; FAYOLLE, P.; DESBOIS, C. Analgesic comparison of meloxicam or ketoprofen for orthopedic surgery in dogs. Veterinary surgery. v.33, p. 650-660, 2004.

DOBSON, J. M.; SAMUEL, S.; MILSTEIN, H.; ROGERS, K.; WOOD, J. L. N. Canine neoplasia in the UK: estimates of incidence rates from a population ofinsured dogs. Journal of Small Animal Practice, v. 43, p. 240-246, 2002.

ENGELHARDT, G.; BÖRGEL, R.; SCHNITZER, C. Meloxicam: influence on arachidonicacid metabolism. Part I. In vitro findings. Biochemestry Pharmacologic. v. 51, p. 21-28, 1996 a.

ENGELHARDT, G.; BÖRGEL, R.; SCHNITZER, C. Meloxicam: influence on arachidonicacid metabolism. Part II. In vitro findings. Biochemestry Pharmacologic. v. 51, p. 29-38, 1996b.

FANTONI, D. T.; KRUMENERL JR, J. L.; GALEGO, M. P. Utilização de analgésicos em pequenos animais. Clínica Veterinária, n. 28, p. 23-33, 2000.

FANTONI, D. T.; MASTROCINQUE, S. Fisiopatologia e controle da dor. In.: FANTONI, D. T.; CORTOPASSI, S. R. G. Anestesia em cães e gatos. São Paulo: Roca. 2002, p. 323-336. 
FRANSSON, P.; DAMBER, J - E.; TOMIC, R.; MODIG, H.; NYBERG, G.; WIDMARK, A. Quality of life and symptons in a randomized trial of radiotherapy versus deferred treatment of localized prostate carcinoma. Cancer, v. 92, n. 12, p. 3111-3119, 2001.

GANZ, P. A.; LEE, J. J.; SIAU, J. Quality-of-life assessment, an independent prognostic variable for survival in lung cancer. Cancer, v. 67, p. 3131-3135, 1991.

GAYNOR, J. S. Pain Management for the Oncology Patient. In: WITHROW, S. J.; MACEWEN, E. G. Small animal clinical oncology, W. B. Saunders Company, 2001. p. 219232.

GIUBLIN, M. L. Tratamento farmacológico. In: CONSENSO NACIONAL DE DOR ONCOLÓGICA, 1., 2002, São Paulo. Anais... São Paulo: Editora de Projetos Médicos, 2002. p. 51-65.

HANSEN, B. Trough a glass darkly: using behaviour to assess pain. Seminars in Veterinary Medicine and Surgery Small Animal, v. 12, n. 2, p. 61-74, 1997.

HASKINS, S. C. Use of analgesics postoperatively in a small animal intensive care setting. Journal of American Veterinary Medical Association, v. 10, p. 1266-1268, 1987.

HELLEBREKERS, L. J. Prefácio. In.: Dor em animais. Barueri: Manole, 2002. p. 9-10.

JALES JUNIOR, L. H.; TEIXEIRA, M. J. Antidepressivos no tratamento da dor. In: TEIXEIRA, M. J.; BRAUM FILHO, J. L.; MARQUEZ, J. O.; YENG, L. T. Dor: contexto interdisciplinar.Curitiba: Editora Maio, 2003. p.613-631.

KAASA, S.; BJORDAL, K.; AARONSON, N.; MOUM, T.; WIST, E.; HAGEN, S.; KVIKSTAD, A. The EORTC core quality of life questionnaire (QLQ-C30): validity and reliability when analysed with patients treated with palliative radiotherapy. European Journal of Pain, v. 31, n. 13-14, p. 2260-2263, 1995.

KADAR, D. Analgésicos antiinflamatórios. In: KALANT, H.; ROSCHLAW, W. H. E. Princípios da farmacologia médica. 5. ed. Rio de Janeiro: Guanabara Koogan, 1989. p. 264273. 
KLAMT, J. G.; REIS, M. P.; PRADO, W. A.; LAURETTI, G. R.; MATTOS, A. L.; GARCIA, L. V. Controle da dor pós-operatória. Medicina Ribeirão Preto, v. 28, n. 7, p. 835-840, 1995.

KORE, A. M. Toxicology of nonsteroidal antiinflammatory drogs. Veterinary Clinic of North American. Small Animal Practices, v. 20, p. 419-430,1990.

LAMONT, L. A.; TRANQUILLI, W. J.; GRIMM, K. A. Physiology of pain. Veterinary Clinic of North America. Small Animal Practices, v. 30, n. 4, p. 703-728, 2000.

LASCELLES, B. D. X.; BUTTERWOR, T. H.; WATERMAN, A. E. Postoperative analgesic and sedative effects of caprofen and phetidine in dogs. Veterinary Record, v. 134, n. 8, p. 187-191, 1994.

LASCELLES, D. Analgesia preoperatória - opiaceos y AINEs. Waltham Focus, v. 9, n. 4, p. 29, 1999.

LASCELlES, D.; WATERMAN, A. Analgesia in cats. In:. Practice, p. 203-213, 1997.

LESTER, P.; GAYNOR, J. S. Management of cancer pain. Veterinary Clinics of North America. Small Animal Practices, v. 30, n. 4, p. 951-966, 2000.

LEWIS, K. S.; HAN, N. H. Tramadol: a new centrally acting analgesic. American Journal of Helth-System Pharmacy, v. 54, n. 6, p. 643-652.

MASTROCINQUE, S. Estudo comparativo entre tramadol e morfina para controle da dor em cadelas portadoras de piometra submetidas à ovariosanpingohiterectomia. 2000.116 f. Dissertação (Mestrado em Cirurgia) - Faculdade de Medicina Veterinária e Zootecnia, Universidade de São Paulo, São Paulo, 2000

MASTROCINQUE, S.; FANTONI, D. T. A comparision of preoperative tramadol and morphine for the control of early postoperative pain in canine and ovariohysterectomy. Veterinary Anaesthesia Analgesia, v. 30, p. 220-228, 2003.

MATHEWS, K. A. Nonsteroidal anti-inflamatory analgesics in pain management in dogs and cats. Canadian Veterinary Journal, v. 37, p. 539-545, 1995. 
MATHEWS, K. A. Nosteroidal anti-inflamatory analgesics - Indications and contraindications for pain management in dogs and cats. Veterinary Clinics of North America: Small Animal Practice, Philadelphia, v. 30, n. 4, p. 783-804, 2000.

MCMILLAN, F. D. A world of hurts - is pain special? Journal of American Veterinary Medical Association, v. 223, n. 2, p. 183-186, 2003a.

MIRANDA, H. F.; PINARDI, G. Antinociception, tolerance, and physical dependence comparissom between morphine and tramadol. Phamacology Biochemistry and Behavior, $\mathrm{v}$. 61, n. 4, p. 357-360, 1998.

MORTON, D. B.; GRIFFITHS, P. H. M. Guidelines on the recognition of pain, distress and discomfort in experimental animals and an hypothesis for assessment. Veterinary Record, $v$. 116, p. 431-436, 1985.

OKADA, M.; TEIXEIRA, M. J.; TENGRAN, S. K. Dor em pediatria. In: TEIXEIRA, M. J.; FIGUEIRÓ, J. A. B. F. Dor: epidemiologia, fisiopatologia, avaliação, síndromes dolorosas e tratamento. São Paulo: Grupo Editorial Moreira Jr., 2001. p. 376-395.

OLIVEIRA, L. F. Dor - mecanismos centrais. In: OLIVEIRA, S. Master dor. São Paulo: Limay, 1998. p.11-18.

OSIPOVA, N. A.; NOVIKOW, G. A.; BERESNEV, V. A. Analgesic effect of tramadol in câncer patients with cronic pain: a comparison with prolonged-action morphine sulfate. Current Therapeutic Research, v.50, p. 812-821, 1991.

OSOBA, D. The quality of life committee of the clinical trials group of the national Cancer Institute of Canada: organization and functions. Quality of Life Research, v. 1, p. 203-211, 1992.

PAPICH, M. G. Principles of analgesic drug therapy. Seminars in Veterinary Medicine and Surgery Small Animal, v. 12, n. 2, p. 80-93, 1997. 
PESSINI, L.; CAPONERO, R.; MELO, A. G. C. Cuidados paliativos: uma necessidade urgente na área de saúde. O Mundo da Saúde, v. 27, n. 1, p. 3-5, 2003.

PIMENTA, C. A. M.; TEIXEIRA, M. J.; NEVES, A. T. A.; PIRROTA, A. C. A Dor e seu controle. São Paulo: FURP, 1998. 20 p.

PORTENOY, R. K.; LESAGE, P. Management of cancer pain. Lancet, n. 353, p. 1695-1700, 1999.

POSSO, I. P.; ROMANACK, R. M.; POSSO, J. P. Inibidores da ciclooxigenase-2. In.: AULER JR., J. O. C. Atualização em anestesiologia I. São Paulo: Atheneu, 1994. p. 47-59.

PROSCHOWSKY, H. F.; RUGBJERG, H.; ERSBOLL, A. K. Mortality of purebred and mixedbreed dogs in Denmark. Preventive Veterinary Medicine, v. 58, p. 63-74, 2003.

RADBRUCH, L.; GROND, S.; LEHMANN, K. A. A Risk-benefit assessment of tramadol in the management of pain. Drug Safety, v. 15, n. 1, p. 8-29, 1996

RAEKALLIO, M. R.; HILEM-BIJÖRKMAN, A. K.; KEJONEN, J; SALONEN, H; SANKARI, S. M. Evaluation of adverse effectes of lon-term orally administered carprofen in dogs. Journal of American Veterinary Medical Association. v. 228, n. 6, p. 876-880, 2006.

REIG, E. Tramadol in musculoskeletal. Clinical Rheumatology, p. S9-S12, Suplemento 1.

RICO. M. A.; CURA, M. A.; HARBIST, H.; PALOMINOS, A.; FIGUEROA, M.; KRAMER, V. Evaluación de tramadol como un opioide alternativo a la codeína en el segundo peldaño de escalera analgésica de la OMS. Revista de la Sociedade Española de la Dolor. v. 7, p. 345-353.

ROBERTSON, S. A. What is pain? Journal of American Veterinary Medical Association, v. 221, n. 2, p. 202-205, 2002.

RODRIGUES, N.; PEREIRA, E. R. Tramadol in cancer pain. Current Theraprutic Research. v. 46, n. 6, p. 1142-1148, 1989. 
RODRÍGUEZ, M.; BARUTELL, C.; RULL, M.; GÁLVEZ, R.; PALLARÉS, J.; VIDAL, F.; ALIAGA, L.; MORENO, J.; PUERTA, J.; ORTIZ, P. Efficacy and tolerance of oral dipyrone versus oral morphine for cancer pain. European Journal of Cancer, v. 30, n. 5, p. 584-587, 1994.

SAKATA, R. K. Tratamento da dor no doente com câncer. In: TEIXEIRA, M. J.; FIGUEIRÓ, J. A. B. F. Dor: epidemiologia, fisiopatologia, avaliação, síndromes dolorosas e tratamento. São Paulo: Grupo Editorial Moreira Jr., 2001. p. 201-207.

SCHOELLER, M. T. Dor oncológica. In: CONSENSO NACIONAL DE DOR ONCOLÓGICA, 1., 2002, São Paulo. Anais... São Paulo: Editora de Projetos Médicos, 2002. p. 13-18.

SKAER, T. L.; PHARM, B. Management of Pain in the Cancer Patient. Clinical Therapeutics,. v. 15, n. 4, p. 638-649, 1993.

SLATER, M. R.; BARTON, C. L.; ROGERS, K. S.; PETERSON, J. L.; HARRIS, C. K.; WALLACE, K. Factors affecting treatment decisions and satisfaction of owners of cats with cancer. Journal of American Veterinary Medical Association, v. 208, n. 8, p. 1248-1255, 1996.

SOUSA, F. F. Mensuração da dor. In: CONSENSO NACIONAL DE DOR ONCOLÓGICA, 1., 2002, São Paulo. Anais... São Paulo: Editora de Projetos Médicos, 2002. p. 19-32.

SPRANGERS, M. A. G. Quality-of-life assessment of oncology. Acta Oncologica , v. 41, p. 229-237, 2002.

TASAKA, A. C. Antiinflatórios não esteroidais. In.: SPINOSA, H. S.; GORNIAK, S. L.; BERNARDI, M. M. Farmacologia aplicada a medicina veterinária. 2. ed. Rio de Janeiro: Guanabara Koogan, 1999. p. 212-222.

TEIXEIRA, M. J. Dor no doente com câncer. In: TEIXEIRA, M. J.; FIGUEIRO, J. A. B. Dor: epidemiologia, fisiologia, avaliação, síndromes dolorosas e tratamento. São Paulo: Grupo Editorial Moreira Jr, 2001. p. 193-200.

TEIXEIRA, M. J. Fisiopatologia da dor. In: TEIXEIRA, M. J. Dor: tratamento farmacológico da dor. São Paulo: Editora Maio, 1999. p. 47-77. 
TEIXEIRA, M. J.; PIMENTA, C. A. M. Avaliação do doente com dor. In: TEIXEIRA, M. J.; FIGUEIRÓ, J. A. B. F. Dor: epidemiologia, fisiopatologia, avaliação, síndromes dolorosas e tratamento. São Paulo: Grupo Editorial Moreira Jr.,2001. p. 58-68.

TEIXEIRA, M. J.; OKADA, M.; TEIXEIRA, W. G. J. Eficácia analgésica e tolerabilidade do tramadol. Revista Brasileira de Medicina, v. 56, n. 4, p. 287-293, 1999.

YAZBEK, K. V. B.; Manutenção da qualidade de vida em cães com câncer:tratamento da dor e cuidados paliativos. 2005. 114 f. Tese (Doutorado em Medicina Veterinária) - Faculdade de Medicina Veterinária e Zootecnia, Universidade de São Paulo, São Paulo, 2005.

YAZBEK, K. V. B.; FANTONI, D. T. Validity of a health-related, quality-of-life scale for dogs with signs of pain secondary to cancer. Journal of American Veterinary Medical Association, v. 226, n. 8, p.1354-1358, 2005.

YAZBEK, K. V. B.; FANTONI, D. T.; MACHADO, A.; MATSUDA, E. I.; ALMEIDA, T. I. Estudo comparativo entre o tramadol e flunexin-meglumine no controle da dor pós-operatória em cães. CONGRESSO BRASILEIRO DA ASSOCIAÇÃO DE CLÍNICOS VETERINÁRIOS DE PEQUENOS ANIMAIS, 20, 1999, Lindóia, Anais...

WILLIAMS, H. J. Tramadol hydrochloride: something new in oral analgesic therapy. Current Therapeutic Research, v. 58, n. 4, p. 215-226.

WISEMAN, M. L.; NOLAN, A. M.; REID, J.; SCOTT, E. M. Preliminary study on ownerreported behaviour changes associated with chronic pain in dogs. Veterinary Record, v. 149, p. 423-424, 2001.

WITHROW, S. J. Why worry about cancer in pets? In: WITHROW, S. J.; MACEWEN, E. G. Small animal clinical oncology. W. B. Saunders Company, 2001. p. 219-232. 
APÊNDICES

FLÔR, P. B. 
APÊNDICE A

Quadro de medicações entregue para todos os proprietários

\begin{tabular}{|c|c|c|c|c|c|c|c|c|c|c|c|}
\hline Nome: & \multicolumn{8}{|c|}{ Prontuário: } & \multicolumn{3}{|c|}{ Data: / / } \\
\hline $\begin{array}{ll}\text { Medicamentos } & \text { Horário } \\
\end{array}$ & $4 \mathrm{~h}$ & $6 \mathrm{~h}$ & $8 \mathrm{~h}$ & $10 \mathrm{~h}$ & $12 \mathrm{~h}$ & $14 \mathrm{~h}$ & $16 \mathrm{~h}$ & $18 \mathrm{~h}$ & $20 \mathrm{~h}$ & $22 \mathrm{~h}$ & $24 \mathrm{~h}$ \\
\hline 1 & & & & & & & & & & & \\
\hline 2 & & & & & & & & & & & \\
\hline 3 & & & & & & & & & & & \\
\hline 4 & & & & & & & & & & & \\
\hline 5 & & & & & & & & & & & \\
\hline 6 & & & & & & & & & & & \\
\hline 7 & & & & & & & & & & & \\
\hline 8 & & & & & & & & & & & \\
\hline 9 & & & & & & & & & & & \\
\hline 10 & & & & & & & & & & & \\
\hline
\end{tabular}


APÊNDICE B

\begin{tabular}{|c|c|c|c|c|c|}
\hline Número & Nome & $\begin{array}{c}\text { Prontuário } \\
\text { HOVET }\end{array}$ & Raça & $\begin{array}{l}\text { Idade } \\
\text { (anos) }\end{array}$ & Sexo \\
\hline 1 & Hooch & 139849 & $\mathrm{SRD}^{1}$ & 13 & Macho \\
\hline 2 & Panki & 127199 & $\mathrm{SRD}^{1}$ & 9 & Fêmea \\
\hline 3 & Smira & 153832 & Cocker Spaniel & 13 & Fêmea \\
\hline 4 & Nelly & 153685 & $\mathrm{SRD}^{1}$ & 10 & Fêmea \\
\hline 5 & Laika & 154436 & Pastor Alemão & 8 & Fêmea \\
\hline 6 & Ralph & 154134 & Poodle & 2 & Macho \\
\hline 7 & Ursa & 134567 & Pastor Alemão & 8 & Fêmea \\
\hline 8 & Paco & 154680 & Poodle & 14 & Macho \\
\hline 9 & Wendy & 154702 & Dachshund & 4 & Fêmea \\
\hline 10 & Atila & 46765 & Boxer & 10 & Macho \\
\hline 11 & Canaã & 153657 & Rottweiler & 10 & Fêmea \\
\hline 12 & Pupi & 40392 & $\mathrm{SRD}^{1}$ & 12 & Fêmea \\
\hline 13 & Carol & 155711 & Mastin Napolitano & 10 & Fêmea \\
\hline 14 & Kirra & 154331 & Pit Bull & 10 & Fêmea \\
\hline 15 & Pitucha & 102806 & Fox Paulistinha & 10 & Fêmea \\
\hline 16 & Roller & 156184 & Labrador & 10 & Fêmea \\
\hline 17 & Kuma & 155333 & Akita & 10 & Macho \\
\hline 18 & Astor & 156495 & Akita & 10 & Macho \\
\hline 19 & Tina & 151263 & Fila Brasileiro & 13 & Fêmea \\
\hline 20 & Toby & 156029 & Rottweiller & 5 & Macho \\
\hline 21 & Agata & 63149 & Boxer & 10 & Fêmea \\
\hline 22 & Shumi & 156577 & Pastor Alemão & 0,5 & Macho \\
\hline 23 & Princesa & 156584 & $\mathrm{SRD}^{1}$ & 11 & Fêmea \\
\hline 24 & Nona & 155658 & Rottweiller & 6 & Fêmea \\
\hline 25 & Filomena & 147902 & Bassethound & 6 & Fêmea \\
\hline 26 & Sadan & 157090 & $\mathrm{SRD}^{1}$ & 10 & Macho \\
\hline 27 & Sandrinha & 157290 & Pastor Alemão & 5 & Fêmea \\
\hline 28 & Pedrita & 157218 & Poodle & 11 & Fêmea \\
\hline 29 & Billy & 157223 & Boxer & 9 & Macho \\
\hline 30 & Vitória & 154948 & Rottweiller & 10 & Fêmea \\
\hline 31 & Yngwie & 157379 & Poodle & 13 & Macho \\
\hline 32 & Negão & 155256 & $\mathrm{SRD}^{1}$ & 4 & Macho \\
\hline 33 & Zeus & 157057 & Rottweiller & 5 & Macho \\
\hline 34 & Catuxa & 158080 & $\mathrm{SRD}^{1}$ & 11 & Fêmea \\
\hline 35 & Kuro & 150375 & $\mathrm{SRD}^{1}$ & 10 & Fêmea \\
\hline 36 & Tryska & 158186 & Boxer & 0,6 & Fêmea \\
\hline 37 & Fred & 158156 & Pastor Alemão & 8 & Macho \\
\hline 38 & Bilu & 147966 & $\mathrm{SRD}^{1}$ & 12 & Fêmea \\
\hline 39 & Duque & 158193 & Dog Alemão & 7 & Macho \\
\hline 40 & Sofia & 158699 & $\mathrm{SRD}^{1}$ & 2 & Fêmea \\
\hline 41 & Princesa & 136075 & $\mathrm{SRD}^{1}$ & 11 & Fêmea \\
\hline 42 & Jerry Lee & 149996 & Pastor Alemão & 11 & Macho \\
\hline 43 & Piter & 150434 & Rottweiller & 8 & Macho \\
\hline 44 & King & 138617 & $\mathrm{SRD}^{1}$ & 10 & Macho \\
\hline 45 & Luana & 126517 & Poodle & $\mathrm{D}^{2}$ & Fêmea \\
\hline
\end{tabular}

1- SRD: Sem raça definida

2- D: Desconhecida

Quadro 2 - Número de identificação, nome, número do prontuário de inscrição no Hospital Veterinário da FMVZ-USP, raça, idade (anos) e sexo dos cães atendidos durante o estudo (cães número 1 a 45) 
APÊNDICE C

\begin{tabular}{|c|c|c|c|c|c|}
\hline Número & Nome & $\begin{array}{c}\text { Prontuário } \\
\text { HOVET }\end{array}$ & Raça & $\begin{array}{l}\text { Idade } \\
\text { (anos) }\end{array}$ & Sexo \\
\hline 46 & Atila & 33705 & Dobermann & 12 & Macho \\
\hline 47 & Tomy & 156488 & Pastor Alemão & 9 & Macho \\
\hline 48 & Winne & 96425 & Bassethound & 12 & Fêmea \\
\hline 49 & Thor & 150364 & Rottveiller & 9 & Macho \\
\hline 50 & Bambina & 159666 & Labrador & 8 & Fêmea \\
\hline 51 & Lord & 160068 & Setter Irlandês & $\mathrm{D}^{2}$ & Macho \\
\hline 52 & Glória & 71039 & Poodle & 14 & Fêmea \\
\hline 53 & Tide & 160860 & Pequinês & 14 & Macho \\
\hline 54 & Xuxa & 47011 & $\mathrm{SRD}^{1}$ & 12 & Fêmea \\
\hline 55 & Bianca & 161187 & Rottweiller & 11 & Fêmea \\
\hline 56. & Juma & 135229 & Fox Paulistinha & 14 & Fêmea \\
\hline 57 & Marrom & 162076 & $\mathrm{SRD}^{1}$ & 9 & Macho \\
\hline 58 & Dog & 77894 & Fox Paulistinha & 15 & Macho \\
\hline 59 & Vermelhinho & 161192 & Mastiff Inglês & 11 & Macho \\
\hline 60 & Mocinha & 154318 & $\mathrm{SRD}^{1}$ & $\mathrm{D}^{2}$ & Fêmea \\
\hline 61 & Cuqui & 137703 & Dachshund & 12 & Fêmea \\
\hline 62 & Otto & 155942 & Boxer & 12 & Macho \\
\hline 63 & Simba & 84360 & Dog Alemão & 8 & Macho \\
\hline 64 & Kaway & 160732 & Lhasa Apso & 10 & Fêmea \\
\hline 65 & Bianca & 13732 & Schnauzer & 13 & Fêmea \\
\hline 66 & Butty & 159224 & $\mathrm{SRD}^{1}$ & 12 & Macho \\
\hline 67 & Hanna & 145529 & Fila Brasileiro & 7 & Fêmea \\
\hline 68 & Monique & 163038 & Poodle & 11 & Fêmea \\
\hline 69 & Susi & 163039 & $\mathrm{SRD}^{1}$ & 17 & Fêmea \\
\hline 70 & Рaco & 162825 & Rottweiller & 8 & Macho \\
\hline 71 & Sunny & 162107 & Rottweiller & 12 & Fêmea \\
\hline 72 & Baby & 121125 & Poodle & 12 & Fêmea \\
\hline 73 & Paty & 161821 & Fox Paulistinha & 10 & Fêmea \\
\hline 74 & Duquesa II & 156314 & Pastor Belga & 11 & Fêmea \\
\hline 75 & Nion & 163701 & Pastor Alemão & 12 & Macho \\
\hline 76 & Talita & 162650 & Cocker Spaniel & 16 & Fêmea \\
\hline 77 & Nara & 164036 & Fila Brasileiro & 16 & Fêmea \\
\hline 78 & Dara Maria & 164545 & $\mathrm{SRD}^{1}$ & 8 & Fêmea \\
\hline 79 & Raí & 159847 & Pastor Alemão & 10 & Macho \\
\hline 80 & Теса & 49722 & $\mathrm{SRD}^{1}$ & 10 & Fêmea \\
\hline 81 & Babi & 164989 & Poodle & 11 & Fêmea \\
\hline 82 & Sansão & 163337 & Rottweiller & 7 & Macho \\
\hline 83 & Tico & 150457 & $\mathrm{SRD}^{1}$ & 12 & Macho \\
\hline 84 & Tuca & 164608 & Pastor Alemão & 13 & Fêmea \\
\hline 85 & Yuki & 155448 & Poodle & 15 & Macho \\
\hline 86 & Petit & 104980 & Husky Siberiano & 12 & Fêmea \\
\hline 87 & Popai & 94896 & Weimaraner & 12 & Macho \\
\hline 88 & $\begin{array}{c}\text { Maria } \\
\text { Eduarda }\end{array}$ & 164843 & Setter Irlandês & 8 & Fêmea \\
\hline 89 & Preta & 98239 & $\mathrm{SRD}^{1}$ & 9 & Fêmea \\
\hline 90 & Pipen & 165639 & $\mathrm{SRD}^{1}$ & 10 & Macho \\
\hline
\end{tabular}

3- SRD: Sem raça definida.

4- D: Desconhecida.

Quadro 3 - Número de identificação, nome, número do prontuário de inscrição no Hospital Veterinário da FMVZ-USP, raça, idade (anos) e sexo dos cães atendidos durante o estudo (cães número 46 a 90) 
APÊNDICE D

\begin{tabular}{|c|c|c|c|c|c|}
\hline Número & Nome & $\begin{array}{c}\text { Prontuário } \\
\text { HOVET }\end{array}$ & Raça & $\begin{array}{l}\text { Idade } \\
\text { (anos) }\end{array}$ & Sexo \\
\hline 91 & Doly & 128147 & Poodle & 12 & Macho \\
\hline 92 & Xuxa & 56351 & Pinscher & 17 & Macho \\
\hline 93 & Led Zeplin & 156694 & Pastor Alemão & 13 & Fêmea \\
\hline 94 & Fênix & 165824 & Husky Siberiano & 4 & Macho \\
\hline 95 & Hanna & 166374 & $\mathrm{SRD}^{1}$ & 14 & Fêmea \\
\hline 96 & Pandora & 166705 & Rottweiller & 10 & Macho \\
\hline 97 & Bana & 141033 & Cocker Spaniel & 12 & Fêmea \\
\hline 98 & Aici & 162589 & $\mathrm{SRD}^{1}$ & 14 & Macho \\
\hline 99 & Greta & 166795 & Pastor Alemão & 10 & Fêmea \\
\hline 100 & Pupi & 167726 & Poodle & 13 & Fêmea \\
\hline 101 & Tuca & 107825 & $\mathrm{SRD}^{1}$ & 12 & Fêmea \\
\hline 102 & Sniper & 131061 & Rottweiller & 11 & Macho \\
\hline 103 & Chayani & 131136 & Dogo Argentino & 10 & Macho \\
\hline 104 & Chen Lee & 81144 & Shar-pei & 12 & Macho \\
\hline 105 & Willie & 167591 & $\mathrm{SRD}^{1}$ & 13 & Fêmea \\
\hline 106 & Petrus & 168244 & Fila Brasileiro & 4 & Fêmea \\
\hline 107 & $\begin{array}{l}\text { Charlie } \\
\text { Brown }\end{array}$ & 18023 & Poodle & 15 & Macho \\
\hline 108 & Amin & 168378 & Old English Sheep Dog & 11 & Macho \\
\hline 109 & Tinin & 168349 & Pastor Alemão & 12 & Fêmea \\
\hline 110 & Duquesa & 156314 & Pastor Belga & 11 & Fêmea \\
\hline 111 & Babalu & 167904 & $\mathrm{SRD}^{1}$ & 11 & Fêmea \\
\hline 112 & Susi & 169028 & Dobermann & 13 & Fêmea \\
\hline 113 & Ralf & 163583 & Boxer & 9 & Macho \\
\hline 114 & Lisa & 155235 & $\mathrm{SRD}^{1}$ & 7 & Fêmea \\
\hline 115 & Tequila & 170301 & $\mathrm{SRD}^{1}$ & 10 & Fêmea \\
\hline 116 & Kiki & 138255 & Pinscher & 14 & Fêmea \\
\hline 117 & Nana & 168188 & Boxer & 6 & Fêmea \\
\hline 118 & Hering & 142536 & $\mathrm{SRD}^{1}$ & 13 & Fêmea \\
\hline 119 & Sandy & 133202 & Rottweiller & 9 & Fêmea \\
\hline 120 & Maggie & 170640 & $\mathrm{SRD}^{1}$ & 10 & Fêmea \\
\hline 121 & Spencer & 169213 & Labrador & 10 & Macho \\
\hline 122 & Roger & 170263 & Rottweiller & 6 & Macho \\
\hline 123 & Chiquita & 124443 & $\mathrm{SRD}^{1}$ & 12 & Fêmea \\
\hline 124 & Tobias & 170696 & Bassethound & 5 & Macho \\
\hline 125 & Zazá & 167947 & SRD & 13 & Fêmea \\
\hline 126 & Morgana & 103406 & Cocker Spaniel & 8 & Fêmea \\
\hline 127 & Baby & 173312 & Golden Retriever & 12 & Macho \\
\hline 128 & Sacha & 173318 & Pastor Alemão & 11 & Fêmea \\
\hline 129 & Tuxa & 172499 & Husky Siberiano & 13 & Fêmea \\
\hline 130 & Ralf & 170499 & Husky Siberiano & 12 & Macho \\
\hline
\end{tabular}

5- SRD: Sem raça definida.

Quadro 4 - Número de identificação, nome, número do prontuário de inscrição no Hospital Veterinário da FMVZ-USP, raça, idade (anos) e sexo dos cães atendidos durante o estudo (cães número 91 a 130) 
APÊNDICE E

\begin{tabular}{|c|c|}
\hline $\begin{array}{l}\text { Número } \\
\text { do } \\
\text { animal }\end{array}$ & Diagnóstico \\
\hline 1 & Carcinoma em testículo e metástase pulmonar \\
\hline 2 & Neoplasia hepática e metástase pulmonar \\
\hline 3 & Neoplasia óssea e metástase pulmonar \\
\hline 4 & Neoplasia óssea \\
\hline 5 & Neoplasia de partes moles \\
\hline 6 & Carcinoma epidermóide em fossa nasal e palato \\
\hline 7 & Neoplasia de partes moles e metástase pulmonar \\
\hline 8 & Neoplasia óssea e metástase em costela \\
\hline 9 & Neoplasia mamária e metástase em tórax \\
\hline 10 & Neoplasia de partes moles \\
\hline 11 & Metástase pulmonar após amputação por neoplasia óssea \\
\hline 12 & Neoplasia mamária e metástase pulmonar \\
\hline 13 & Neoplasia de partes moles e metástase pulmonar \\
\hline 14 & Mastocitoma e metástase cutânea \\
\hline 15 & Carcinoma cutâneo e metástase pulmonar \\
\hline 16 & Neoplasia de partes moles e metástase pulmonar \\
\hline 17 & Hemangiossarcoma e metástase pulmonar \\
\hline 18 & Neoplasia hepática e esplênica \\
\hline 19 & Metástase pulmonar após amputação por neoplasia óssea \\
\hline 20 & Neoplasia de partes moles \\
\hline 21 & Neoplasia de partes moles e metástase pulmonar \\
\hline 22 & Neoplasia óssea \\
\hline 23 & Neoplasia óssea \\
\hline 24 & Sarcoma em osso frontal e fossas nasais \\
\hline 25 & Linfoma histiocístico e rabdomiossarcoma \\
\hline 26 & Neoplasia nasal e oral \\
\hline 27 & Neoplasia hepática e esplênica \\
\hline 28 & Neoplasia pulmonar primária \\
\hline 29 & Neoplasia hepática, esplênica, renal e metástase pulmonar \\
\hline 30 & Neoplasia óssea recidivante após amputação \\
\hline 31 & Melanoma em cavidade oral e metástase pulmonar \\
\hline 32 & Neoplasia em mediastino \\
\hline 33 & Neoplasia de partes moles e metástase pulmonar \\
\hline 34 & Neoplasia mamária e metástase pulmonar \\
\hline 35 & Metástase pulmonar após mastectomia por neoplasia mamária \\
\hline 36 & Neoplasia óssea \\
\hline 37 & Neoplasia óssea e metástase pulmonar \\
\hline 38 & Neoplasia de partes moles e metástase pulmonar \\
\hline 39 & Neoplasia óssea \\
\hline 40 & Neoplasia pulmonar primária \\
\hline 41 & Metástase pulmonar após mastectomia pos neoplasia mamária \\
\hline 42 & Metástase pulmonar após amputação por neoplasia óssea \\
\hline 43 & Neoplasia óssea e metástase pulmonar \\
\hline 44 & Neoplasia de partes moles e metástase pulmonar \\
\hline 45 & Neoplasia de partes moles e metástase pulmonar \\
\hline
\end{tabular}

Quadro 5 - Diagnóstico instituído dos cães de número 1 a 45 
APÊNDICE F

\begin{tabular}{|c|c|}
\hline $\begin{array}{l}\text { Número } \\
\text { do } \\
\text { animal }\end{array}$ & Diagnóstico \\
\hline 46 & Metástase pulmonar após excisão de neoplasia cutânea \\
\hline 47 & Metástase em ossos da face após ablação de conduto auditivo por carcinoma \\
\hline 48 & Neoplasia de partes moles \\
\hline 49 & Neoplasia óssea \\
\hline 50 & Neoplasia Hepática \\
\hline 51 & Neoplasia óssea e metástase pulmonar \\
\hline 52 & Neoplasia mamária e metástase pulmonar \\
\hline 53 & Neoplasia óssea \\
\hline 54 & Metástase pulmonar após excisão de neoplasia de partes moles \\
\hline 55 & Neoplasia óssea e metástase pulmonar \\
\hline 56 & Metástase pulmonar após hemimandibulectomia por carcinoma \\
\hline 57 & Neoplasia de partes moles e metástase pulmonar \\
\hline 58 & Neoplasia óssea \\
\hline 59 & Neoplasia óssea \\
\hline 60 & Neoplasia de partes moles \\
\hline 61 & Carcinoma de próstata e neoplasia hepática e renal \\
\hline 62 & Neoplasia em bolsa escrotal \\
\hline 63 & Neoplasia óssea \\
\hline 64 & Neoplasia de partes moles \\
\hline 65 & Neoplasia hepática \\
\hline 66 & Hemangiossarcoma em mandíbula \\
\hline 67 & Neoplasia óssea \\
\hline 68 & Neoplasia mamária e metástase pulmonar \\
\hline 69 & Neoplasia mamária \\
\hline 70 & Neoplasia óssea e metástase pulmonar \\
\hline 71 & Neoplasia de partes moles \\
\hline 72 & Metástase pulmonar após excisão de neoplasia de partes moles \\
\hline 73 & Neoplasia mamária e neoplasia de partes moles \\
\hline 74 & Neoplasia hepática \\
\hline 75 & Neoplasia hepática e esplênica \\
\hline 76 & Linfoma cutâneo \\
\hline 77 & Neoplasia pulmonar primária \\
\hline 78 & Neoplasia óssea \\
\hline 79 & Neoplasia de partes moles \\
\hline 80 & Neoplasia intestinal \\
\hline 81 & Metástase pulmonar e óssea após excisão de neoplasia mamária \\
\hline 82 & Neoplasia óssea \\
\hline 83 & Neoplasia óssea \\
\hline 84 & Metástase pulmonar após excisão de neoplasia mamária \\
\hline 85 & Neoplasia em fosas nasais e palato \\
\hline 86 & Neoplasia óssea \\
\hline 87 & Neoplasia hepática e de partes moles \\
\hline 88 & Neoplasia óssea \\
\hline 89 & Neoplasia pulmonar primária \\
\hline 90 & Neoplasia óssea \\
\hline
\end{tabular}

Quadro 6 - Diagnóstico instituído dos cães de número 46 a 90 
APÊNDICE G

\begin{tabular}{|c|c|}
\hline $\begin{array}{l}\text { Número } \\
\text { do } \\
\text { animal }\end{array}$ & Diagnóstico \\
\hline 91 & Neoplasia vesical \\
\hline 92 & Neoplasia hepática \\
\hline 93 & Neoplasia óssea \\
\hline 94 & Neoplasia hepática \\
\hline 95 & Neoplasia de partes moles \\
\hline 96 & Neoplasia óssea \\
\hline 97 & Neoplasia pulmonar \\
\hline 98 & Neoplasia de partes moles e metástase pulmonar. \\
\hline 99 & Neoplasia óssea \\
\hline 100 & Metástase cutânea após excisão de neoplasia mamária \\
\hline 101 & Neoplasia óssea \\
\hline 102 & Metástase óssea após excisão de neoplasia mamária \\
\hline 103 & Hemagiossarcoma cutâneo \\
\hline 104 & Neoplasia hepática \\
\hline 105 & Neoplasia óssea \\
\hline 106 & Neoplasia óssea \\
\hline 107 & Neoplasia óssea \\
\hline 108 & Metástase pulmonar após excisão de neoplasia mamária \\
\hline 109 & Neoplasia óssea \\
\hline 110 & Neoplasia hepática \\
\hline 111 & Neoplasia hepática e perianal \\
\hline 112 & Neoplasia óssea \\
\hline 113 & Neoplasia óssea, testicular e metástase pulmonar \\
\hline 114 & Neoplasia óssea \\
\hline 115 & Neoplasia mamária e metástase em linfonodos axilares. \\
\hline 116 & Metástase cutânea e pulmonar após excisão de neoplasia mamária \\
\hline 117 & Linfoma \\
\hline 118 & Neoplasia mamária e diversos nódulos cutâneos \\
\hline 119 & Neoplasia hepática \\
\hline 120 & Neoplasia mamária e metástase cutânea \\
\hline 121 & Neoplasia óssea \\
\hline 122 & Neoplasia óssea \\
\hline 123 & Neoplasia hepática e esplênica \\
\hline 124 & Neoplasia hepática \\
\hline 125 & Neoplasia de partes moles em região axilar \\
\hline 126 & Neoplasia óssea e metástase pulmonar \\
\hline 127 & Neoplasia óssea \\
\hline 128 & Neoplasia de partes moles e metástase pulmonar \\
\hline 129 & Neoplasia mamária e metástase pulmonar \\
\hline 130 & Neoplasia em seios nasais \\
\hline
\end{tabular}

Quadro 7 - Diagnóstico instituído dos cães de número 91 a 130 


\section{APÊNDICE H}

\begin{tabular}{|c|c|c|}
\hline $\begin{array}{l}\text { Número } \\
\text { do } \\
\text { animal }\end{array}$ & Principais alterações e sinais relatados & $\begin{array}{c}\text { Período de } \\
\text { tempo } \\
\text { (dias) } \\
\end{array}$ \\
\hline 1 & Dificuldade respiratória, perda de apetite. & 24 \\
\hline 2 & Dificuldade deglutir, fraqueza. & 60 \\
\hline 3 & Paralisia dos membros. & 21 \\
\hline 4 & Claudicação. & 60 \\
\hline 5 & Claudicação, prostração. & 60 \\
\hline 6 & Espirros, engasgos, sangramento nasal, halitose. & Não sabe \\
\hline 7 & Percepção do tumor. & 90 \\
\hline 8 & Perda de apetite, dor, dificuldade sentar e deitar. & 30 \\
\hline 9 & Percepção do tumor, perda apetite, emagrecimento. & 60 \\
\hline 10 & Percepção do tumor, perda apetite, dificuldade respiratória. & 60 \\
\hline 11 & Dor coluna e membro, decúbito. & 90 \\
\hline 12 & Dificuldade respiratória. & 90 \\
\hline 13 & Não soube informar. & - \\
\hline 14 & Feridas no corpo coceira. & 150 \\
\hline 15 & Diarréia e vômitos. & 180 \\
\hline 16 & Dor para defecar. & 60 \\
\hline 17 & Dor coluna e membro, decúbito. & 120 \\
\hline 18 & Dor, perda de apetite, dificuldade de sentar. & 30 \\
\hline 19 & Percepção do tumor, cansaço fácil, emagrecimento. & 180 \\
\hline 20 & Percepção do tumor, cansaço. & 60 \\
\hline 21 & Tosse e emagrecimento. & 90 \\
\hline 22 & Claudicação. & 60 \\
\hline 23 & Claudicação, urina escura. & 30 \\
\hline 24 & Dificuldade respiratória, sangramento nasal. & 150 \\
\hline 25 & Dificuldade de deglutir. & 15 \\
\hline 26 & Percepção do tumor. & 120 \\
\hline 27 & Perda de apetite, vômitos e apatia. & 25 \\
\hline 28 & Tosse e perda de apetite. & 60 \\
\hline 29 & Perda de apetite e emagrecimento. & 90 \\
\hline 30 & Dificuldade de defecar e dor em membros. & 10 \\
\hline 31 & Dor na boca, salivação excessiva. & 30 \\
\hline 32 & Emagrecimento, perda de apetite, dificuldade de deglutir. & 300 \\
\hline 33 & Percepção do tumor, dor, perda de apetite. & 60 \\
\hline 34 & Lambedura do tumor, tosse, dificuldade respiratória. & 17 \\
\hline 35 & Engasgos, tosse. & 7 \\
\hline 36 & Dor, dificuldade locomotora. & 120 \\
\hline 37 & Claudicação, perda de apetite, percepção do tumor. & 30 \\
\hline 38 & Dor, percepção do tumor. & 90 \\
\hline 39 & Claudicação, dor em membro. & 90 \\
\hline 40 & Percepção do tumor, perda de apetite. & 45 \\
\hline
\end{tabular}

Quadro 8 - Principais alterações e sinais relatados na primeira consulta pelos proprietários dos cães de número 1 a 40 e período de tempo (dias) desde o início das alterações 


\section{APÊNDICE I}

\begin{tabular}{|c|c|c|}
\hline $\begin{array}{c}\text { Número } \\
\text { do } \\
\text { animal }\end{array}$ & Principais alterações e sinais relatados & $\begin{array}{c}\text { Período de } \\
\text { tempo } \\
\text { (dias) }\end{array}$ \\
\hline 41 & Dificuldade respiratória. & 8 \\
\hline 42 & Tosse. & 390 \\
\hline 43 & Perda de apetite, dor, não anda, dificuldade respiratória. & 20 \\
\hline 44 & Dor, percepção do tumor, lambedura do tumor. & 60 \\
\hline 45 & Dor, dificuldade locomotora. & 120 \\
\hline 46 & Dificuldade respiratória, tosse. & 120 \\
\hline 47 & Percepção do tumor, úlceras. & 120 \\
\hline 48 & Dificuldade de defecar, dor, perda de apetite. & 60 \\
\hline 49 & Claudicação, dor. & 15 \\
\hline 50 & Não apresenta sinais. & - \\
\hline 51 & Percepção do tumor, claudicação, dor, cansaço fácil. & 30 \\
\hline 52 & Dificuldade locomotora, edema de membros, perda de apetite. & 30 \\
\hline 53 & Percepção do tumor, dor, prostração. & 10 \\
\hline 54 & Perda de apetite, engasgos, tosse, cansaço fácil. & Não sabe \\
\hline 55 & Percepção do tumor, dor. & 60 \\
\hline 56 & Tosse. & 540 \\
\hline 57 & Vômitos. & 90 \\
\hline 58 & Dor, vocalização, dificuldade de sentar. & 60 \\
\hline 59 & Claudicação, percepção do tumor. & 60 \\
\hline 60 & Percepção do tumor, perda de apetite, prostração. & 60 \\
\hline 61 & Fezes pastosas e enegrecidas. & 60 \\
\hline 62 & Dor. & 60 \\
\hline 63 & Percepção do tumor, dor. & 15 \\
\hline 64 & Apática. & 150 \\
\hline 65 & Perda de apetite, incontinência urinária, dorme muito. & 13 \\
\hline 66 & Dificuldade locomotora. & 60 \\
\hline 67 & Claudicação. & 30 \\
\hline 68 & Dor, percepção do tumor, tosse. & 30 \\
\hline 69 & Dor, percepção do tumor, perda de apetite. & 150 \\
\hline 70 & Tremores, prostração, emagrecimento. & 60 \\
\hline 71 & Claudicação, percepção do tumor. & 90 \\
\hline 72 & Dor. & 365 \\
\hline 73 & Percepção do tumor, dor. & 240 \\
\hline 74 & Ferida em boca, dor à palpação. & 30 \\
\hline 75 & Tosse, insônia, perda de apetite. & 45 \\
\hline 76 & Percepção do tumor, dor, claudicação. & 180 \\
\hline 77 & Emagrecimento, perda de apetite. & 14 \\
\hline 78 & Dor, dificuldade locomotora. & 15 \\
\hline 79 & Perda de apetite, emagrecimento. & 45 \\
\hline 80 & Andar em círculos. & 60 \\
\hline
\end{tabular}

Quadro 9 - Principais alterações e sinais relatados na primeira consulta pelos proprietários dos cães de número 41 a 80 e período de tempo (dias) desde o início das alterações 
APÊNDICE J

\begin{tabular}{|c|c|c|}
\hline $\begin{array}{l}\text { Número } \\
\text { do } \\
\text { animal }\end{array}$ & Principais alterações e sinais relatados & $\begin{array}{c}\text { Período de } \\
\text { tempo } \\
\text { (dias) }\end{array}$ \\
\hline 81 & Não anda dor dificuldade respiratória. & 30 \\
\hline 82 & Dor, claudicação. & 240 \\
\hline 83 & Percepção do tumor, claudicação. & 90 \\
\hline 84 & Dor, dificuldade de andar,sentar e levantar, perda de apetite. & 30 \\
\hline 85 & $\begin{array}{l}\text { Espirros, sangramento nasal. } \\
\end{array}$ & 365 \\
\hline 86 & Claudicação. & 120 \\
\hline 87 & Perda de apetite. & 30 \\
\hline 88 & Dor, perda de apetite. & 30 \\
\hline 89 & Dificuldade respiratória, insônia. & 20 \\
\hline 90 & Não anda, decúbito, perda de apetite, urina deitado. & 30 \\
\hline 91 & Urina com sangue. & 60 \\
\hline 92 & Não apresenta sinais ou alterações. & - \\
\hline 93 & Dificuldade de andar, levantar e de se manter em estação. & 365 \\
\hline 94 & Perda de apetite, tristeza. & 15 \\
\hline 95 & Dificuldade de subir escadas, fezes achatadas. & 180 \\
\hline 96 & Claudicação. & 120 \\
\hline 97 & Dificuldade de defecar. & 90 \\
\hline 98 & Dor, dificuldade de levantar, cansaço. & 90 \\
\hline 99 & Impotência funcional de membro. & 90 \\
\hline 100 & $\begin{array}{l}\text { Prostração, edema de membros, dor para deitar, dificuldade de } \\
\text { manter-se em estação, feridas em mamas e percepção do tumor. }\end{array}$ & 35 \\
\hline 101 & Perda de apetite e vômito. & 180 \\
\hline 102 & Claudicação. & 30 \\
\hline 103 & Percepção do tumor. & Não sabe \\
\hline 104 & Não apresenta sinais ou alterações. & - \\
\hline 105 & Claudicação, dificuldade de andar. & 60 \\
\hline 106 & Claudicação, dor. & 30 \\
\hline 107 & Urina em gotejamento, de coloração rósea. & 90 \\
\hline 108 & Percepção do tumor, cansaço, perda de apetite. & 365 \\
\hline 109 & Percepção do tumor. & 30 \\
\hline 110 & Dificuldade respiratória, dor, perda de apetite. & 150 \\
\hline 111 & Percepção do tumor, dificuldade de defecar. & 240 \\
\hline 112 & Claudicação, percepção do tumor, Edema de membro, dor. & 90 \\
\hline 113 & Claudicação. & 210 \\
\hline 114 & Lambedura de membro. & 30 \\
\hline 115 & Dor, percepção do tumor. & 30 \\
\hline 116 & Perda de apetite, prostração, tristeza. & 2 \\
\hline 117 & Vômitos, perda de apetite, dor. & 7 \\
\hline 118 & Claudicação, percepção do tumor, dor. & 60 \\
\hline 119 & Perda de apetite, aumento na ingestão de água, vocalização. & 30 \\
\hline
\end{tabular}

Quadro 10 - Principais alterações e sinais relatados na primeira consulta pelos proprietários dos cães de número 81 a 119 e período de tempo (dias) desde o início das alterações 


\section{APÊNDICE K}

\begin{tabular}{|c|c|c|}
\hline $\begin{array}{c}\text { Número } \\
\text { do } \\
\text { animal }\end{array}$ & Principais alterações e sinais relatados & $\begin{array}{c}\text { Período de } \\
\text { tempo } \\
\text { (dias) }\end{array}$ \\
\hline 120 & Dor, perda de apetite, fezes escuras, percepção do tumor, \\
decúbito. & 60 \\
\hline 121 & Dor, claudicação, cansaço. & 90 \\
\hline 122 & Percepção do tumor. & 20 \\
\hline 123 & Dor. & 90 \\
\hline 124 & Aumento de volume abdominal, perda de apetite. & 120 \\
\hline 125 & Claudicação, dor. & 180 \\
\hline 126 & Dificuldade de urinar, claudicação. & 30 \\
\hline 127 & Vômito, perda de apetite, fezes escuras e amolecidas. & 10 \\
\hline 128 & Vômito, diarréia, dificuldade respiratória. & 7 \\
\hline 129 & Prostração. & 7 \\
\hline 130 & Percepção do tumor, sangramento nasal e espirros. & 210 \\
\hline
\end{tabular}

Quadro 11 - Principais alterações e sinais relatados na primeira consulta pelos proprietários dos cães de número 120 a 130 e período de tempo (dias) desde o início das alterações 
APÊNDICE L

\begin{tabular}{|c|c|}
\hline $\begin{array}{l}\text { Número } \\
\text { do } \\
\text { animal }\end{array}$ & Motivos de Exclusão \\
\hline 1 & Proprietário não medicou corretamente \\
\hline 2 & Eutanásia antes de tratamento com tramadol. \\
\hline 5 & $\begin{array}{l}\text { Não retornou após o início do tratamento com dipirona e antiinflamatório não } \\
\text { esteroidal. }\end{array}$ \\
\hline 6 & $\begin{array}{c}\text { Não retornou após o início do tratamento com dipirona e antiinflamatório não } \\
\text { esteroidal. }\end{array}$ \\
\hline 7 & $\begin{array}{c}\text { Não retornou após o início do tratamento com dipirona e antiinflamatório não } \\
\text { esteroidal. }\end{array}$ \\
\hline 8 & Eutanásia antes de 15 dias de tratamento com tramadol. \\
\hline 10 & $\begin{array}{c}\text { Não retornou após o início do tratamento com dipirona e antiinflamatório não } \\
\text { esteroidal }\end{array}$ \\
\hline 11 & Animal irascível impossibilitando exame físico. \\
\hline 12 & Não retornou após o início do tratamento com tramadol. \\
\hline 13 & Não retornou após o início do tratamento com dipirona. \\
\hline 14 & $\begin{array}{c}\text { Não retornou após o início do tratamento com dipirona e antiinflamatório } \\
\text { esteroidal }\end{array}$ \\
\hline 16 & Eutanásia antes de tratamento com tramadol. \\
\hline 17 & Óbito antes de tratamento com tramadol. \\
\hline 18 & Não retornou após o início do tratamento com tramadol. \\
\hline 19 & Proprietário não soube quantificar a dor através da escala estabelecida. \\
\hline 20 & Proprietário não soube quantificar a dor através da escala estabelecida. \\
\hline 21 & Animal sendo medicado com outro opióide fraco. \\
\hline 22 & $\begin{array}{c}\text { Não retornou após o início do tratamento com dipirona e antiinflamatório não } \\
\text { esteroidal. }\end{array}$ \\
\hline 24 & Não retornou após o início do tratamento com dipirona. \\
\hline 25 & Eutanásia antes de tratamento com tramadol. \\
\hline 26 & Não retornou após o início do tratamento com tramadol. \\
\hline 27 & Não retornou após o início do tratamento com dipirona. \\
\hline 28 & O valor atribuído à dor foi menor que 4. \\
\hline 32 & $\begin{array}{l}\text { Não retornou após o início do tratamento com dipirona e antiinflamatório não } \\
\text { esteroidal. }\end{array}$ \\
\hline 33 & $\begin{array}{l}\text { Não retornou após o início do tratamento com dipirona e antiinflamatório não } \\
\text { esteroidal. }\end{array}$ \\
\hline 34 & Animal sendo medicado com outro opióide fraco. \\
\hline 35 & O valor atribuído à dor foi menor que 4. \\
\hline 36 & Eutanásia antes de 15 dias de tratamento com tramadol. \\
\hline 37 & $\begin{array}{c}\text { Não retornou após o início do tratamento com dipirona e antiinflamatório não } \\
\text { esteroidal. }\end{array}$ \\
\hline 38 & $\begin{array}{c}\text { Não retornou após o início do tratamento com dipirona e antiinflamatório não } \\
\text { esteroidal. }\end{array}$ \\
\hline 40 & Animal sendo medicado com outro opióide fraco. \\
\hline 41 & $\begin{array}{l}\text { Não retornou após o início do tratamento com dipirona e antiinflamatório } \\
\text { esteroidal. }\end{array}$ \\
\hline 42 & O valor atribuído à dor foi menor que 4. \\
\hline 45 & Não retornou após o início do tratamento com tramadol. \\
\hline
\end{tabular}

Quadro 12 - Número do animal e motivo pelo qual foi excluído do estudo 
APÊNDICE M

\begin{tabular}{|c|c|}
\hline $\begin{array}{l}\text { Número } \\
\text { do } \\
\text { animal }\end{array}$ & Motivos de Exclusão \\
\hline 46 & Proprietário não medicou corretamente \\
\hline 50 & Óbito antes de 15 dias de tratamento com tramadol. \\
\hline 52 & $\begin{array}{l}\text { Não retornou após o início do tratamento com dipirona e antiinflamatório não } \\
\text { esteroidal. }\end{array}$ \\
\hline 53 & $\begin{array}{l}\text { Não retornou após o início do tratamento com dipirona e antiinflamatório não } \\
\text { esteroidal. }\end{array}$ \\
\hline 54 & O valor atribuído à dor foi menor que 4. \\
\hline 55 & Eutanásia antes de 15 dias de tratamento com tramadol. \\
\hline 56 & O valor atribuído à dor foi menor que 4. \\
\hline 57 & O valor atribuído à dor foi menor que 4. \\
\hline 58 & Não retornou após o início do tratamento com tramadol. \\
\hline 59 & Não retornou após o início do tratamento com tramadol. \\
\hline 60 & Não retornou após o início do tratamento com tramadol. \\
\hline 62 & Não foi medicado com dipirona. \\
\hline 63 & O valor atribuído à dor foi menor que 4. \\
\hline 66 & Dor crônica não oncológica. \\
\hline 68 & Não retornou após o início do tratamento com tramadol. \\
\hline 72 & Não retornou após o início do tratamento com tramadol. \\
\hline 73 & Não retornou após o início do tratamento com dipirona. \\
\hline 74 & $\begin{array}{l}\text { Não retornou após o início do tratamento com dipirona e antiinflamatório não } \\
\text { esteroidal. }\end{array}$ \\
\hline 75 & Animal sendo medicado com outro opióide fraco. \\
\hline 76 & Não retornou após o início do tratamento com dipirona. \\
\hline 77 & Não retornou após o início do tratamento com dipirona. \\
\hline 78 & Não retornou após o início do tratamento com tramadol. \\
\hline 79 & Não retornou após o início do tratamento com dipirona. \\
\hline 80 & Não retornou após o início do tratamento com tramadol. \\
\hline 81 & $\begin{array}{l}\text { Não retornou após o início do tratamento com dipirona e antiinflamatório não } \\
\text { esteroidal. }\end{array}$ \\
\hline 82 & Não retornou após o início do tratamento com tramadol. \\
\hline 84 & Eutanásia antes de 15 dias de tratamento com tramadol. \\
\hline 85 & Proprietário não medicava corretamente. \\
\hline 87 & Proprietário não medicava corretamente. \\
\hline 88 & Não retornou após o início do tratamento com tramadol. \\
\hline 89 & Animal sendo medicado com outro opióide fraco. \\
\hline 91 & $\begin{array}{c}\text { Não retornou após o início do tratamento com dipirona e antiinflamatório } \\
\text { esteroidal. }\end{array}$ \\
\hline 92 & Não retornou após o início do tratamento com dipirona. \\
\hline 94 & Não retornou após o início do tratamento com dipirona. \\
\hline 95 & Não retornou após o início do tratamento com tramadol. \\
\hline 96 & Eutanásia antes de 15 dias de tratamento com tramadol. \\
\hline 98 & Animal sendo medicado com outro opióide fraco. \\
\hline 99 & Proprietário não medicava corretamente. \\
\hline 101 & $\begin{array}{c}\text { Não retornou após o início do tratamento com dipirona e antiinflamatório } \\
\text { esteroidal }\end{array}$ \\
\hline
\end{tabular}

Quadro 13 - Número do animal e motivo pelo qual foi excluído do estudo 


\section{APÊNDICE N}

\begin{tabular}{|c|c|}
\hline $\begin{array}{c}\text { Número } \\
\text { do } \\
\text { animal }\end{array}$ & Motivos de Exclusão \\
\hline 103 & Não retornou após o início do tratamento com dipirona e antiinflamatório \\
esteroidal
\end{tabular}

Quadro 14 - Número do animal e motivo pelo qual foi excluído do estudo 


\begin{tabular}{|c|c|c|c|c|c|c|c|c|c|}
\hline \multirow[b]{2}{*}{ Animal } & \multicolumn{3}{|c|}{ ENV Pesquisador } & \multicolumn{3}{|c|}{ ENV Proprietário } & \multicolumn{3}{|c|}{ Qualidade de Vida } \\
\hline & Consulta & $\begin{array}{l}\text { Primeiro } \\
\text { Retorno }\end{array}$ & $\begin{array}{l}\text { Segundo } \\
\text { Retorno }\end{array}$ & $\begin{array}{l}\text { Consulta } \\
\text { nata }\end{array}$ & $\begin{array}{l}\text { Primeiro } \\
\text { Retorno }\end{array}$ & $\begin{array}{l}\text { Segundo } \\
\text { Retorno }\end{array}$ & Consulta & $\begin{array}{l}\text { Primeiro } \\
\text { Retorno }\end{array}$ & $\begin{array}{l}\text { Segundo } \\
\text { Retorno }\end{array}$ \\
\hline 15 & 5 & 3 & 2 & 10 & 2 & 2 & 21 & 23 & 21 \\
\hline 29 & 6 & 7 & 3 & 5 & 7 & 3 & 14 & 12 & 19 \\
\hline 31 & 3 & 2 & 1 & 4 & 1 & 2 & 28 & 29 & 29 \\
\hline 48 & 7 & 2 & 0 & 4 & 2 & 0 & 25 & 26 & 31 \\
\hline 61 & 7 & 4 & 5 & 6 & 2 & 4 & 20 & 28 & 26 \\
\hline 65 & 6 & 3 & 3 & 4 & 0 & 0 & 16 & 22 & 28 \\
\hline 97 & 4 & 2 & 2 & 5 & 2 & 2 & 23 & 27 & 27 \\
\hline 123 & 4 & 3 & 3 & 4 & 2 & 2 & 25 & 25 & 27 \\
\hline Média & 5,25 & 3,25 & 2,25 & 5,25 & 2,25 & 1,88 & 21,5 & 24 & 26 \\
\hline Desvio Padrão & 1,49 & 1,67 & 1,49 & 2,05 & 2,05 & 1,36 & 4,75 & 5,40 & 4,04 \\
\hline
\end{tabular}

Quadro 15 - Número do animal, nota de escore de dor (ENV) atribuída pelo pesquisador e pelo proprietário, nota obtida pelo questionário de qualidade de vida no Grupo DT 
APÊNDICE P

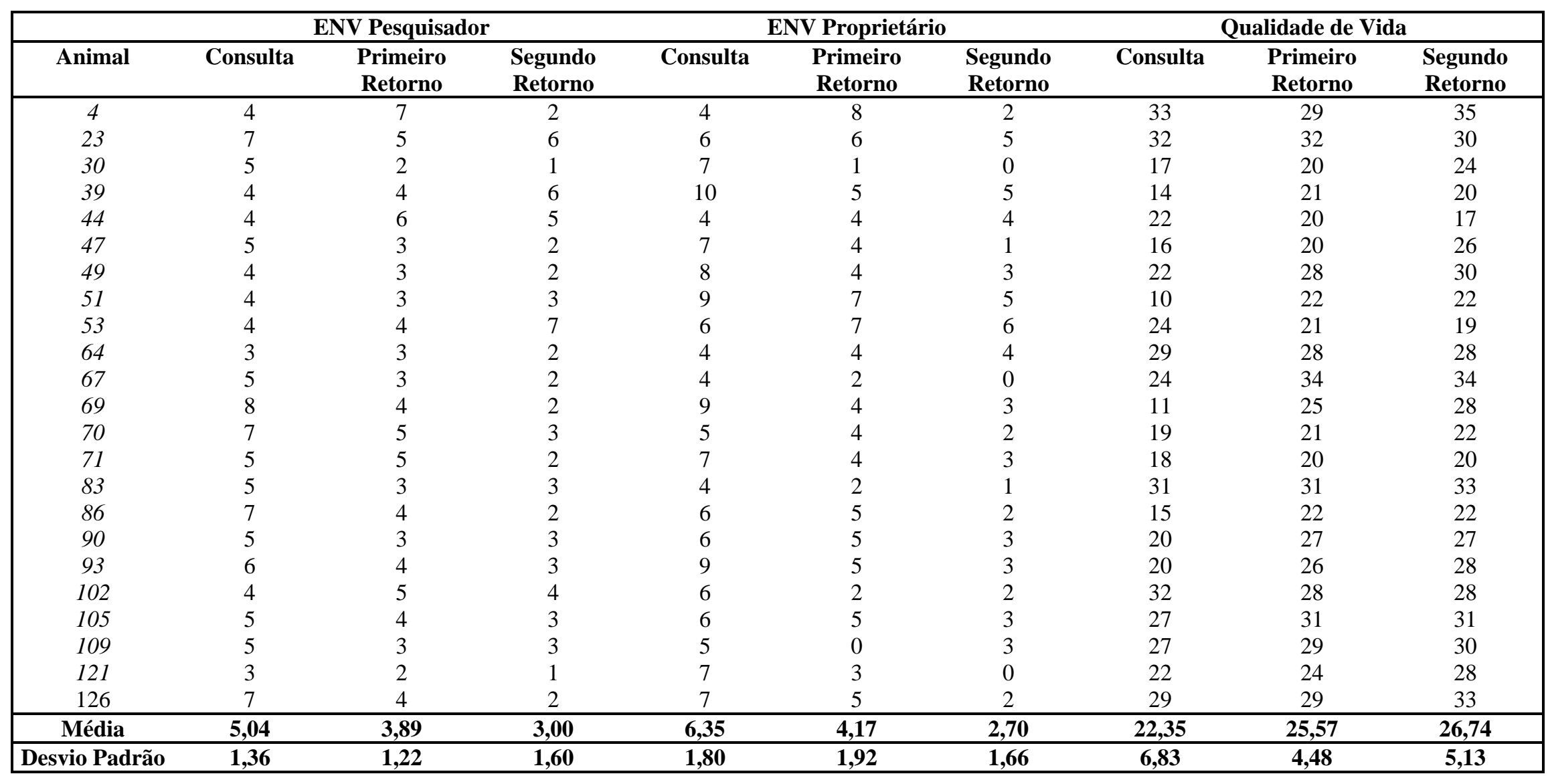

Quadro 16 - Número do animal, nota de escore de dor (ENV) atribuída pelo pesquisador e pelo proprietário, nota obtida pelo questionário de qualidade de vida no Grupo DAINET 


\begin{tabular}{|cccccccccc|}
\hline & \multicolumn{3}{c}{ ENV Pesquisador } & \multicolumn{3}{c}{ ENV Proprietário } & \multicolumn{3}{c|}{ Qualidade de Vida } \\
\hline Animal & Consulta & $\begin{array}{c}\text { Primeiro } \\
\text { Retorno }\end{array}$ & $\begin{array}{c}\text { Segundo } \\
\text { Retorno }\end{array}$ & Consulta & $\begin{array}{c}\text { Primeiro } \\
\text { Retorno }\end{array}$ & $\begin{array}{c}\text { Segundo } \\
\text { Retorno }\end{array}$ & Consulta & $\begin{array}{c}\text { Primeiro } \\
\text { Retorno }\end{array}$ & $\begin{array}{c}\text { Segundo } \\
\text { Retorno }\end{array}$ \\
\hline 3 & 5 & 0 & 1 & 4 & 0 & 0 & 24 & 18 & 28 \\
9 & 6 & 3 & 4 & 6 & 5 & 5 & 24 & 29 & 28 \\
43 & 6 & 4 & 4 & 7 & 4 & 3 & 18 & 27 & 24 \\
100 & 9 & 3 & 6 & 8 & 1 & 7 & 17 & 24 & 20 \\
116 & 6 & 3 & 3 & 7 & 2 & 3 & 17 & 29 & 25 \\
117 & 4 & 2 & 1 & 6 & 1 & 0 & 26 & 36 & 36 \\
\hline Média & $\mathbf{6 , 0 0}$ & $\mathbf{2 , 5}$ & $\mathbf{3 , 1 7}$ & $\mathbf{6 , 3 3}$ & $\mathbf{2 , 1 6}$ & $\mathbf{3}$ & $\mathbf{2 1}$ & $\mathbf{2 7 , 1 7}$ & $\mathbf{2 6 , 8 3}$ \\
\hline Desvio Padrão & $\mathbf{1 , 6 7}$ & $\mathbf{1 , 3 8}$ & $\mathbf{1 , 9 4}$ & $\mathbf{1 , 3 6}$ & $\mathbf{1 , 9 4}$ & $\mathbf{2 , 7 5}$ & $\mathbf{4 , 1 0}$ & $\mathbf{5 , 9 9}$ & $\mathbf{5 , 4 0}$ \\
\hline
\end{tabular}

Quadro 17 - Número do animal, nota de escore de dor (ENV) atribuída pelo pesquisador e pelo proprietário, nota obtida pelo questionário de qualidade de vida no Grupo DET 
ANEXO

FLÔR, P. B. 
ANEXO A

Escala para avaliação da qualidade de vida (versão em português)

\section{seu animal? \\ 0 . ( ) muitíssimo \\ 1. ( ) muito \\ 2. ( ) um pouco \\ 3. ( ) não}

1.Você acha que a doença atrapalha a vida do

2.O seu animal continua fazendo as coisas que gosta (brincar, passear...)?

0.( ) nunca mais fez

1.( ) raramente

o I I fmoriinntomnntn

3. Como está temperamento do seu animal?

0.( ) totalmente alterado

1.( ) alguns episódios de alteração

2.( ) mudou pouco

3.( ) normal

\section{O seu animal manteve os hábitos de higiene}

(lamber-se p. ex.)?

0.( ) não

1.( ) raramente

2.( ) menos aue antes

\section{Você acha que o seu animal sente dor?}

0.( ) sempre

1.( ) freqüentemente

2.( ) raramente

3.( ) nunca

\section{0 seu animal tem apetite?}

0.( ) não

1.( ) só come forçado/só o que gosta

2.( ) pouco

3.( ) normal
7.O seu animal se cansa facilmente?

0.( ) sempre

1.( ) freqüentemente

2.( ) raramente

3.( ) está normal

8.Como está o sono do seu animal?

0.( ) muito ruim

1.( ) ruim

2.( ) bom

3.( ) normal

9.O seu animal tem vômitos?

0.( ) sempre

1.( ) freqüentemente

2.( ) raramente

3.( ) não

10.Como está o intestino do seu animal?

0.( ) péssimo/funciona com dificuldade

1.( ) ruim

2.( ) quase normal

3.( ) normal

11.O seu animal é capaz de se posicionar sozinho para fazer xixi e cocô ?

0.( ) nunca mais conseguiu

1.( ) raramente consegue

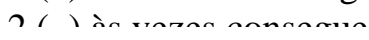

12.Quanta atenção o animal está dando para a família?

0.( ) está indiferente

1.( ) pouca atenção

2.( ) aumentou muito (carência)

3.( ) não mudou/está normal

YAZBEK, K. V. B.; FANTONI, D. T. Validity of a health-related, quality-of-life scale for dogs with signs of pain secondary to cancer. Journal of American Veterinary Medical Association, v. 226, n. 8, p.1354-1358, 2005 